OPEN ACCESS

Edited by: Loretta Tuosto, Sapienza Università

di Roma, Italy

Reviewed by: Michael Loran Dustin, Harvard University, United States

Christoph Wülfing,

University of Bristol,

United Kingdom

*Correspondence:

Elita Avota

elita.avota@vim.uni-wuerzburg.de

Specialty section: This article was submitted to T Cell Biology, a section of the journal Frontiers in Immunology

Received: 03 January 2018 Accepted: 04 April 2018

Published: 18 April 2018

Citation:

Börtlein C, Draeger A, Schoenauer R, Kuhlemann A, Sauer M, Schneider-Schaulies $S$ and Avota E (2018) The Neutral Sphingomyelinase 2 Is Required to Polarize and Sustain

$T$ Cell Receptor Signaling. Front. Immunol. 9:815. doi: 10.3389/fimmu.2018.00815

\section{The Neutral Sphingomyelinase 2 Is Required to Polarize and Sustain T Cell Receptor Signaling}

\author{
Charlene Börtlein', Annette Draeger ${ }^{2}$, Roman Schoenauer', Alexander Kuhlemann ${ }^{3}$, \\ Markus Sauer ${ }^{3}$, Sibylle Schneider-Schaulies ${ }^{1}$ and Elita Avota ${ }^{1 *}$ \\ ${ }^{1}$ Institute for Virology and Immunobiology, University of Wuerzburg, Wuerzburg, Germany, ${ }^{2}$ Department of Cell Biology, \\ Institute for Anatomy, University of Bern, Bern, Switzerland, ${ }^{3}$ Department of Biotechnology and Biophysics, University of \\ Wuerzburg, Wuerzburg, Germany
}

By promoting ceramide release at the cytosolic membrane leaflet, the neutral sphingomyelinase 2 (NSM) is capable of organizing receptor and signalosome segregation. Its role in T cell receptor (TCR) signaling remained so far unknown. We now show that TCR-driven NSM activation is dispensable for TCR clustering and initial phosphorylation, but of crucial importance for further signal amplification. In particular, at low doses of TCR stimulatory antibodies, NSM is required for $\mathrm{Ca}^{2+}$ mobilization and T cell proliferation. NSM-deficient T cells lack sustained CD3 $\zeta$ and ZAP-70 phosphorylation and are unable to polarize and stabilize their microtubular system. We identified PKC $\zeta$ as the key NSM downstream effector in this second wave of TCR signaling supporting dynamics of microtubule-organizing center (MTOC). Ceramide supplementation rescued PKC membrane recruitment and MTOC translocation in NSM-deficient cells. These findings identify the NSM as essential in TCR signaling when dynamic cytoskeletal reorganization promotes continued lateral and vertical supply of TCR signaling components: CD3 Zap70, and $\mathrm{PKC}$, and functional immune synapses are organized and stabilized via MTOC polarization.

Keywords: neutral sphingomyelinase 2, T cells, ceramides, $\mathrm{PKC} \zeta$, the microtubule-organizing center

\section{INTRODUCTION}

$\mathrm{T}$ cell antigen recognition activates a well-defined signaling cascade involving tyrosine kinases and scaffold proteins to promote membrane proximal assembly of the T cell receptor (TCR) signalosome $(1-5)$. This also triggers dynamic reorganization of the actin and tubulin cytoskeleton to sustain $\mathrm{T}$ cell activation, which relies on lateral and vertical transport of microclusters and signalosome components $(6,7)$. Thereby, signal is stabilized and amplified, and functional immune synapses (ISs) are organized as required for propagation and sustainment of TCR signaling (8-12). For this to occur, cytoskeleton-driven polarization of organelles, also including the microtubule-organizing center (MTOC) and the Golgi, toward the IS is a prerequisite to meet demands for enhanced vesicular trafficking of signalosome components (6). Activation of novel protein kinase $\mathrm{C}$ isoforms has been found to be important in this second wave of $\mathrm{T}$ cell activation which relies on stable anchoring of plus ends of acetylated and detyrosinated microtubuli to the peripheral SMAC, which is usually accomplished within $2-5 \mathrm{~min}(13,14)$.

$\mathrm{T}$ cell receptor signal initiation and propagation also strongly depend on dynamic reorganization of lipid membrane domains. These are crucial for activation, segregation, or specific recruitment of signalosome components as well as cytoskeletal anchoring $(10,15,16)$. This applies for instance to 
TCR proximal signal initiation by membrane charge-dependent conformational switching of the CD3e cytoplasmic domain, segregation of phosphatases from active kinases or the need for displacement of cholesterol from the TCR $\beta$ chain (17-22). The lipid environment is decisive for recruitment and activity of Lck and ZAP-70 (23-25), and the importance of $\operatorname{PIP}_{2}(4,5)$ and $\mathrm{PIP}_{3}(3,4,5)$ enriched microdomains in PLC $\gamma$ catalyzed $\mathrm{Ca}^{2+}$ mobilization and recruitment of $\mathrm{PH}$-domain containing proteins, respectively, is well established $(16,26,27)$. Furthermore, microtubuli and actin are reversibly anchored by cytoskeletal linker proteins to defined lipid areas of the IS to mediate mechanical stabilization and directional transport of subsynaptic vesicles $(6,9,13,28)$. In addition to lipid composition and turnover, lipid order and the integrity of lipid ordered domains have been found to be crucial for $\mathrm{T}$ cell activation $(2,16,29-32)$. Those domains are highly organized and contain complex glycosphingolipids, cholesterol, and glycosylphosphatidylinositol-anchored and acetylated proteins. Lipid ordered membrane phases were practically defined by insolubility in non-ionic detergents. Isolation of detergent resistant membranes (DRMs) is widely used as analytic tool to isolate low-density membrane fractions for studies of lateral order of associated proteins even so results are strongly dependent on experimental conditions and seems to be artificial structures that are not present in vivo (33). A specific role for sphingolipids in regulation of lipid ordered domains and $\mathrm{T}$ cell activation, is, however, as yet ill defined.

Sphingomyelin is a major component of the plasma membrane and is a part of lipid ordered domains, and its hydrolysis by acid or neutral sphingomyelinases (ASM or NSM within the extrafacial or inner leaflet of the plasma membrane, respectively) and subsequent ceramide release was found to affect a variety of biological processes (34-38). Production of ceramides in lipid ordered domains containing sphingomyelin leads to formation of ceramide enrichment and hypothetical loss of local cholesterol $(35,39)$. Because of their particular biophysical properties, ceramide-enriched membrane microdomains act to compartmentalize receptors and their proximal signalosomes and thereby regulate cellular signaling (35, 40-42). In T cells, sphingomyelin breakdown and/or ceramide accumulation can interfere with activation: depletion of extrafacial sphingomyelin caused disruption of $\mathrm{PIP}_{2}$ islands at the cytosolic membrane leaflet (26), ASM activity blocked phytohemagglutinin or phorbol-ester (PMA)/ ionomycin stimulated $\mathrm{Ca}^{2+}$ mobilization (43-45), and NSM hyperactivation by measles virus abrogated co-stimulation induced actin cytoskeletal reorganization (46). Accordingly, ceramides are of low abundance in CD3-lipidomes (32) and NSM-depleted $\mathrm{T}$ cells were hyper-responsive to $\alpha$-CD $3 / \alpha-\mathrm{CD} 28$-mediated costimulation (46). There is, however, also evidence that NSM is functionally important in TCR signaling: it is transiently activated in both $\alpha$-CD3 and $\alpha$-CD3/CD28 stimulated T cells, where both the enzyme and ceramides localized to the IS $(46,47)$.

Employing genetic depletion in primary and Jurkat $\mathrm{T}$ cells, we established that NSM activity is not required for initiation of TCR signaling within the first 2 min of stimulation at the level of TCR microcluster formation, CD3 $\zeta$ phosphorylation, and Lck activation, but rather for TCR signal amplification needed for sustained $\mathrm{T}$ cell activation especially when antigen dose and co-stimulatory signals are limiting. TCR-induced sustained phosphorylation of both $\mathrm{CD} 3 \zeta$ and ZAP-70 were not supported in NSM-depleted T cells, nor did these molecules efficiently polarize toward pseudo-ISs. This also applied to the MTOC and this was accompanied by $\alpha$-tubulin destabilization. Importantly, essential components of the polarity complex, Cdc42 and PKC $\zeta$ failed to redistribute to the IS in the absence of NSM, and this was rescued by exogenous ceramide as was MTOC recruitment. Altogether, these findings reveal that NSM activity is dispensable for initiation of TCR signaling, but is of crucial importance for its propagation and sustainment.

\section{MATERIALS AND METHODS}

\section{Ethics Statement}

Primary human cells were obtained from the Department of Transfusion Medicine, University of Wuerzburg, and analyzed anonymously. All experiments involving human material were conducted according to the principles expressed in the Declaration of Helsinki and ethically approved by the Ethical Committee of the Medical Faculty of the University of Wuerzburg.

\section{Isolation of Primary Human T Cells and Generation of NSM KD Cells}

Primary human PBMCs were isolated from peripheral blood obtained from healthy donors by Ficoll gradient centrifugation. CD3+ T cells were enriched $(\geq 90 \%)$ from the PBMC fraction using nylon wool columns (Kisker Biotech $\mathrm{GmbH}$ ). CD4+ $\mathrm{T}$ cells from PBMCs were negatively selected using MagniSort ${ }^{\mathrm{TM}}$ Human CD4 T Cell Enrichment Kit (Invitrogen by Thermo Fisher Scientific). Transfection of primary human T cells was done according to the manufacturer's protocol (Lonza) using the U014 program. For silencing of NSM2, cells were nucleofected twice with an interval of 2 days with 400 pmol siRNA targeting human SMPD3 (NSM2) (48) or, for control, a non-targeting siRNA (Sigma-Aldrich). T cells were used for sphingomyelinase assays and subsequent experiments 5 days post-transfection.

\section{Generation of Jurkat- $\Delta$ NSM Cells}

$1 \times 10^{7}$ Jurkat $\mathrm{T}$ cells were transfected by electroporation $(150 \mathrm{~V})$ with $2 \mu$ g of both the N-SMase 2 CRISPR/Cas9 KO plasmid and the N-SMase2 HDR plasmid constructs (Santa Cruz Biotechnology, Dallas, TX, USA). Cells were grown $\left(37^{\circ} \mathrm{C}, 5 \% \mathrm{CO}_{2}\right)$ for up to 3 days in RPMI1640 medium (10\% FBS) without antibiotics. Efficiency of the N-SMase2 CRISPR/Cas9 KO plasmid transfection was visually confirmed by GFP detection, whereas the successful co-transfection of the N-SMase2 HDR plasmid was visually confirmed by RFP detection. Doubly transfected Jurkat cells were then selected by $1 \mu \mathrm{g} / \mathrm{ml}$ puromycin, starting 3 days after the transfection. The selection medium was replaced every 3 days. After 3 weeks of selection, transcriptional levels of the NSM2 were assayed by qPCR.

\section{RT-PCR}

Total RNA from $2 \times 10^{6}$ NSM2 and control siRNA nucleofected T cells was isolated 5 days post-transfection using TRIzol Reagent 
(Life Technologies) following the manufacturer's protocol. cDNA was synthesized using the First Strand cDNA Synthesis Kit (ThermoFisher Scientific) and used for PCR performed with Phusion Polymerase (ThermoFisher Scientific) and NSM2 cDNA specific PCR primers: forwards 5' GCAGCTTCAAGTGTCTC AACAG 3', reverse 5' GTAGTGGGTGAACAGGGAGTGT 3'.

\section{Sphingomyelinase Assay}

NSM activity was determined as previously described (47) with modifications. $3 \times 10^{6} \mathrm{~T}$ cells were disrupted by freeze/thawing (methanol/dry ice) in NSM lysis buffer without detergents $(20 \mathrm{mM}$ Tris $\mathrm{pH} 7.4,10 \mathrm{mM} \beta$-glycerophosphate, $5 \mu \mathrm{M}$ DTT, protease inhibitors). Nuclei were removed by centrifugation for $5 \mathrm{~min}$ at $1,600 \mathrm{rpm}$. Post-nuclear homogenate was used directly for analysis of NSM silencing efficiency in unstimulated cells or centrifuged for $1 \mathrm{~h}$ at 26,000 rpm in PBS with protease inhibitors for detection of NSM activity in cellular membranes of cells pretreated with $5 \mu \mathrm{M}$ PP2 or not (Invitrogen) for $30 \mathrm{~min}$ at $37^{\circ} \mathrm{C}$ followed by $\alpha$-CD3 stimulation for different time points. Cell extracts were incubated with $1.35 \mathrm{mM}$ HMU-PC in NSM lysis buffer(6hexadecanoylamino-4-methylumbelliferyl-phosphorylcholine) (Moscerdam substrates) at $37^{\circ} \mathrm{C}$ for $17 \mathrm{~h}$ (final volume $30 \mu \mathrm{l}$ ). The ASM assay was done according to protocol provided by Moscerdam for usage of HMU-PC. Fluorescence reading was performed using excitation at $404 \mathrm{~nm}$ and emission at $460 \mathrm{~nm}$ according to the manufacturers' protocol.

\section{T Cell Proliferation Assay}

$1 \times 10^{5} \mathrm{~T}$ cells were pre-incubated with $\alpha$-CD3- (clone UCHT- 1 ) alone or together with CD28-specific antibody (clone CD28.2) (at indicated concentrations) (both: Beckton-Dickinson Biosciences Pharmingen) on ice for $20 \mathrm{~min}$, subsequently transferred to 96-well plates pre-coated with $25 \mu \mathrm{g} / \mathrm{ml} \alpha$-mouse IgG (Dianova) $\left(1 \mathrm{~h}\right.$ at $\left.37^{\circ} \mathrm{C}\right)$. NSM KD or CTRL T cells were stimulated for $72 \mathrm{~h}$ including a final $24 \mathrm{~h}$ labeling period ([3 $\mathrm{H}]$-thymidine) (Amersham), and proliferation was analyzed using a microplate scintillation counter.

\section{Detection of Apoptosis}

CTRL and NSM KD T cells were left unstimulated or stimulated for $24 \mathrm{~h}$ with $\alpha$-CD3 alone or with CD3/CD28-specific Abs in combination as described above (antibody concentration: each $1 \mu \mathrm{g} / \mathrm{ml}$ ). When indicated $400 \mathrm{ng} / \mathrm{ml}$ FasL (kindly provided by Harald Wajant, University of Würzburg) was added to $\alpha$-CD3/ CD28 stimulated cells for $3 \mathrm{~h}$. Apoptotic cells were detected by flow cytometry using the eBioscience Annexin V Apoptosis Detection Kit (ThermoFisher Scientific).

\section{Detection of Membrane Order, $\mathrm{Ca}^{2+}$ Mobilization, TCR Signaling, and Endocytosis \\ Membrane Order}

$\mathrm{T}$ cells were resuspended in $4 \mu \mathrm{M}$ di-4-ANEPPDHQ (ANE, Invitrogen) in $\mathrm{PBS}$ for $20 \mathrm{~min}$ at $37^{\circ} \mathrm{C}$. Fluorescence was detected at wavelengths of $570 \mathrm{nM}$ (FL2 channel) and $630 \mathrm{nM}$ (FL3 channel) in living cells by flow cytometry using FACS Calibur (Becton Dickinson) and analyzed by FlowJo software (TreeStar).

\section{$\mathrm{Ca}^{2+}-$ Mobilization Experiments}

Following a washing step, $\mathrm{T}$ cells $\left(1 \times 10^{6}\right)$ were loaded with $1 \mu \mathrm{M}$ Fluo-4 as cell-permanent AM ester (Molecular Probes, Invitrogen) in Hanks balanced salt solution (without $\mathrm{CaCl}_{2}$, $\mathrm{MgSO}_{4}$, and phenol red) containing 5\% FCS and $25 \mathrm{mM} \mathrm{HEPES}$ ( $\mathrm{pH} 7.5$ ) according to manufacturers' protocol. Indicated concentrations of $\alpha$-CD3 antibody (clone UCHT-1; Beckton-Dickinson Biosciences Pharmingen) crosslinked with goat $\alpha$-mouse IgG (Fc $\gamma$ Fragment Specific; Jackson ImmunoResearch) were added in complete Hanks medium (supplemented with $1 \mathrm{mM} \mathrm{CaCl}_{2}$ ) and $\mathrm{Ca}^{2+}$ flux over time was determined by flow cytometry.

Phosphorylated CD3 $\zeta$ and Zap70 proteins in $\alpha$-CD3-stimulated primary and Jurkat $\mathrm{T}$ cells were detected by flow cytometry using Alexa488 fluorophore conugated pCD3ל(Y142) (clone K25407.69) and pZap70(Y319) specific antibodies (Beckton-Dickinson Biosciences Pharmingen). Cells were stimulated by $\alpha-\mathrm{CD} 3$ Ab crosslinked with goat $\alpha$-mouse IgG (ratio 1:1) (final concentration: $5 \mu \mathrm{g} / \mathrm{ml}$ each) on ice for $15 \mathrm{~min}$ followed by transfer to $37^{\circ} \mathrm{C}$ for different time intervals. Stimulation was stopped on ice. Cells were immediately fixed (4\% PFA/PBS) on ice and at room temperature (20 min each) followed by extensive washing, overnight incubation with antibody in $0.33 \%$ saponin/PBS buffer at $4^{\circ} \mathrm{C}$, and analyzed by flow cytometry.

$\mathrm{T}$ cell receptor endocytosis was analyzed as previously described (49). $10^{7}$ cells $/ \mathrm{ml} \mathrm{T}$ cells were washed twice with cold PBS, incubated with $5 \mu \mathrm{g} / \mathrm{ml} \alpha$-CD3 antibody for $30 \mathrm{~min}$ on ice, shifted to $37^{\circ} \mathrm{C}$, and endocytosis was stopped by incubating cells on ice and adding cold PBS prior to flow cytometry.

\section{Image Acquisition for dSTORM Analyses}

CTRL and Jurkat- $\triangle$ NSM cells were seeded into 8-well PolyD-Lysin coated Lab-Teks (Lab-Tek II, Nunc; Thermo Fischer Scientific) $\left(1.5 \times 10^{5}\right.$ cells/well $)$ and adhered for $24 \mathrm{~h}$ at $37^{\circ} \mathrm{C}$. Alexa Fluor 647 conjugated $\alpha$-human CD3 antibody (UCHT1 clone, BioLegend) was pre-incubated with goat $\alpha$-mouse IgG, Fcy Fragment Specific (Jackson ImmunoResearch) for $25 \mathrm{~min}$ at RT (ratio $1: 1,5 \mu \mathrm{g} / \mathrm{ml}$ ). Cells were cooled on ice for $10 \mathrm{~min}$, stained with antibody-Fc solution for $30 \mathrm{~min}$ and left on ice for unstimulated samples or stimulated by 5 or $10 \mathrm{~min}$ incubation at $37^{\circ} \mathrm{C}$. Cells were washed twice with ice-cold PBS and re-stained with $5 \mu \mathrm{g} / \mathrm{ml} \alpha$-CD3 antibodies for $30 \mathrm{~min}$ on ice. Cells were fixed ( $4 \%$ formaldehyde/ $0.2 \%$ glutaraldehyde) for $15 \mathrm{~min}$ at RT, washed three times with $\mathrm{PBS}$ and stored at $4^{\circ} \mathrm{C}$ until imaging. Confocal images were acquired on a LSM-700 (Zeiss) equipped with a Plan-Apochromat $63 \times 1.4$ oil objective. Alexa Fluor 647 fluorophores were excited with $5 \%$ transmission of a $5 \mathrm{~mW}$ solid-state laser at $639 \mathrm{~nm}$. The emission light was detected by a photomultiplier. All images were normalized to gray values ranging from 1 to 5,000 using ImageJ (50). Super-resolution imaging of CD3 molecules was performed in switching buffer $(\mathrm{pH} 7.4)$ containing $100 \mathrm{mM} \beta$-mercaptoethylamine (Sigma-Aldrich) in PBS. dSTORM measurements were performed using an Olympus IX-71 inverted wide-field fluorescence microscope equipped with an oil-immersion objective (60×, NA 1.45; Olympus). A $639 \mathrm{~nm}$ diode laser (Toptica) was used to excite Alexa Fluor 647 fluorophores. The excitation light was spectrally cleaned by a clean-up filter (Laser Clean-up filter 640/10; Chroma). Emission 
light was filtered by a dichroic mirror (HC560/659; Semrock) and a longpass filter (LP647; Semrock) and then projected onto an electron-multiplying CCD camera (iXon DU-897; Andor). Addition of lenses in the detection path led to a final pixel size of $134 \mathrm{~nm}$. Total internal reflection fluorescence illumination was used for imaging of CD3 molecules on the basal membrane of the cells. For each dSTORM measurement 15,000 images with an exposure time of $20 \mathrm{~ms}$ and an irradiation intensity of $\sim 5 \mathrm{~kW} / \mathrm{cm}^{2}$ were recorded.

\section{dSTORM Image Reconstruction and Data Analysis}

The software rapidSTORM 3.2 was used to localize singlemolecule events in all recorded images, to generate a localization file with all localizations, and to reconstruct the dSTORM image. Localizations containing less than 1,400 photons per frame were discarded. The spatial distribution of CD3 localizations was analyzed with custom-written Mathematica code (Mathematica, Version 11.0, Wolfram Research Inc., Champaign, IL, USA). We defined the basal membrane of each cell with all detected localizations as region of interest (ROI). For each ROI, localization clusters that represent single CD3 entities (target protein with primary antibody) or collections thereof were identified using the DBSCAN algorithm (eps $=20 \mathrm{~nm}$, minPts = 3). Various cluster properties were then calculated and clustered localizations with a cluster area less than $100 \mathrm{~nm}^{2}$ were discarded. We compared the cluster density in each ROI and the localization density in each cluster for wild type and $\Delta$ NSM Jurkat cells.

\section{Cell Stimulation, DRM Isolation, and Western Blot Analysis}

For DRM analyses, $2.5 \times 10^{7}$ Jurkat or Jurkat- $\Delta$ NSM cells were left unstimulated or were stimulated in $200 \mu$ of Hanks balanced salt solution (containing $1 \mathrm{mM}$ HEPES, $\mathrm{pH} \mathrm{7.5)}$ ) at $37^{\circ} \mathrm{C}$ for 5 min with $3 \mu \mathrm{g}$ of $\alpha$-CD3 antibody (clone UCHT-1) premixed and crosslinked with $3 \mu \mathrm{g}$ of goat $\alpha$-mouse IgG. Stimulation was stopped by ice-cold Brij98 lysis buffer and lysates were subjected to sucrose gradient ultracentrifugation as previously described. For Western blot analyses, $2 \times 10^{6}$ primary T cells or $1.5 \times 10^{6}$ Jurkat cells were stimulated for the time intervals indicated by $\alpha$ CD3 antibody crosslinked with goat $\alpha$-mouse $\operatorname{IgG}(5 \mu \mathrm{g} / \mathrm{ml}$ each) in solution or Jurkat cells were stimulated by PMA $(40 \mathrm{ng} / \mathrm{ml})$ and ionomycin $(2.5 \mu \mathrm{g} / \mathrm{ml})$, lysed in $40 \mu \mathrm{l}$ Western blot sample buffer, freezed at $-80^{\circ} \mathrm{C}$ followed by boiling for $5 \mathrm{~min}$.

pTyr were detected using mouse monoclonal antibody specific for tyrosine-phosphorylated protein species (clone 4G10, Millipore). p-Lck(Y505), pSrc(Y416) (rabbit mAb, D4964), pCD3ל

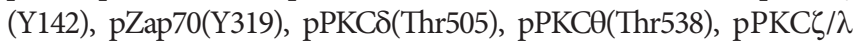
(Thr410/403), and acetyl- $\alpha$-tubulin(Lys40) (rabbit mAb, D20G3) antibodies (all from Cell Signaling) were used to detect stimulationdependent phosphorylation of signaling molecules. Antibodies specific for $\mathrm{CD} 3 \zeta$, PKCO (rabbit $\mathrm{mAb}$, clone E1I7Y), tubulin (mouse mAb, clone DM1A) (all from Cell Signaling), and GAPDH (Santa Cruz) were used to control protein loading and normalize phosphorylation signal. PKC $\zeta$ [rabbit $\mathrm{mAb}$, clone EP1490(2)] from Abcam; CD3e (rat mAb, clone CD3-12), LAT (rabbit polyclonal, FL-233), and Lck (mouse mAb, clone 73A5) antibodies from Santa Cruz were used to detect DRM associated PKCל. Quantification of signal intensities was performed using Li-Cor software (Li-Cor Biosciences).

\section{Analysis of IL-2 Production}

$1 \times 10^{5}$ Jurkat or Jurkat- $\Delta$ NSM cells were stimulated for $48 \mathrm{~h}$ with PMA and ionomycin at concentrations described for Western blot analysis. Supernatants were collected and used for IL-2 detection by ELISA (human IL-2 ELISA Ready-SET-GO, Invitrogen).

\section{Immunofluorescence Analysis}

For pseudo-IS formation, $2 \times 10^{5} \mathrm{NSM} \mathrm{KD}$ or CTRL T cells were stimulated for $15 \mathrm{~min}$ at $37^{\circ} \mathrm{C}$ in $100 \mu \mathrm{l}$ RPMI $1640 / 0.5 \%$ BSA with $\alpha$-CD3 (UCHT1)-coated beads (Dynabeads M-450 Tosylactivated, coated after manufacturer's instructions, Invitrogen) at a ratio of 2:1 and captured onto a poly-L-lysine-coated slides (LabTekII, Nunc).

For Jurkat and Jurkat- $\Delta$ NSM cell polarization analysis, $1 \times 10^{5}$ cells were pre-incubated with $\alpha$-CD3 antibodies (clone UCHT- 1 ) $(1 \mu \mathrm{g} / \mathrm{ml})$ on ice for $20 \mathrm{~min}$, subsequently transferred to 8 -well Nunc glass slides pre-coated with $25 \mu \mathrm{g} / \mathrm{ml} \alpha$-mouse IgG (Dianova) $\left(1 \mathrm{~h}\right.$ at $\left.37^{\circ} \mathrm{C}\right)$ and stimulated for $15 \mathrm{~min}$ at $37^{\circ} \mathrm{C}$. When indicated Jurkat cells were pretreated with $10 \mu \mathrm{M}$ PKCל pseudosubstrate inhibitor (PZI) (Santa Cruz) or Jurkat- $\Delta$ NSM cells with $10 \mu \mathrm{M}$ glycogen synthase kinase $3 \beta$ (GSK3 $\beta$ ) inhibitor indirubin-3'-monoxime (IMO) (Cayman Chemical) for $30 \mathrm{~min}$ before cell transfer to stimulatory slides.

T cell activation was stopped by adding warm 4\% PFA (in PBS) for $20 \mathrm{~min}$ at RT. Cells were permeabilized with $0.1 \%$ Triton-X100 for $5 \mathrm{~min}$, blocked with $5 \%$ BSA, and incubated with primary antibodies specific for: TCR $\beta$ (rabbit polyclonal, H-197) (Santa Cruz), Zap70 (rabbit mAb, clone 99F2) (Cell Signaling), PKCל (rabbit mAb, clone EP1490(2)) (Abcam), Cdc42-Alexa488 (mouse mAb, B-8) (Santa Cruz), $\beta$-tubulin (rabbit mAb, clone 9F3) (Cell Signaling), and detyrosinated $\alpha$-tubulin (rabbit polyclonal) (Abcam) diluted in $1 \% \mathrm{BSA} / \mathrm{PBS}$ overnight at $4^{\circ} \mathrm{C}$. Cells were stained with $\alpha$-rabbit Alexa488-conjugated secondary antibody (Invitrogen) for $1 \mathrm{~h}$ at RT. F-actin was detected with 555 fluorochrom-conjugated phalloidin (cytoskeleton). To ensure that reduced fluorescence signal intensities for some signaling molecules in NSM-deficient T cells are not based on differential membrane folding, cells were loaded with fluorescent plasma membrane dye octadecyl rhodamine B chloride R18 (Sigma-Aldrich, Germany) before pseudo-synapse formation. Samples were mounted with fluorochrome G (Southern Biotech). Confocal Laser Scanning Microscopy imaging was performed using a LSM 510 Meta (Zeiss, Germany), equipped with an inverted Axiovert 200 microscope and a $40 \times$ or $63 \times$ EC Plan-Apo oil objective (numerical aperture 1.3 or 1.4 , respectively) and laser lines 488 and 543. Image acquisition was performed with Zeiss LSM software 3.2 SP2. When indicated, $0.17 \mu \mathrm{m}$ thick $\mathrm{z}$-stacks were acquired and 3-dimensional reconstructed using LSM. ImageJ free software was used to analyze mean fluorescence intensities of ROIs set at pseudo-IS, plasma membrane marked by F-actin staining or inside the cell area. 
TCR $\beta$, Zap70, PKC $\zeta$, and PKC $\theta$ IS interface accumulation was counted as positive if relative fluorescence increase at IS was more than 1.5 in relation to surface fluorescence intensity or intracellular accumulation. Immunofluorescence pictures were taken randomly without unconscious search of expected fluorescence patterns and all cells visible in the field were analyzed. At least 70 up to 150 cells were analyzed per condition.

\section{Labeling With Functionalized $\omega-\mathrm{C}_{16}$ Ceramide}

A total of $2.5 \times 10^{7}$ Jurkat or Jurkat- $\triangle$ NSM were extensively washed and resuspended in RPMI/2\% FBS containing $25 \mu \mathrm{M}$ $\omega$-azido- $\mathrm{C}_{16}$-ceramide (51), incubated overnight at $37^{\circ} \mathrm{C}$ and washed three times with HBSS. For click reaction, $20 \mu \mathrm{M}$ ClickIT Alexa 488 DIBO Alkyne (Life Technologies) was added for $10 \mathrm{~min}$ and cells were microscopically analyzed for labeling efficiency and ceramide plasma membrane accumulation. Ceramide supplemented Jurkat cells were stimulated by $\alpha$-CD3 antibody and used for lipid raft isolation, polarization on stimulatory surface followed by immunofluorescence analysis of tubulin or detection of $\mathrm{pCD} 3 \zeta$ by flow cytometry.

\section{Statistical Analyses}

Overall, data shown were acquired in at least three independent experiments and involved different individual donors when primary human $\mathrm{T}$ cells were used. Anderson-Darling test revealed non-normal distribution for some data sets. Therefore, non-parametric and distribution free Kolmogorov-Smirnov test was used for statistical analyses of all data sets throughout the manuscript $\left({ }^{*} p<0.05,{ }^{* *} p<0.005\right.$, and ${ }^{* *} p<0.0001$; ns, nonsignificant). Bars show SDs.

\section{RESULTS}

\section{NSM Activity Is Required for TCR Signaling When Antigen Dose Is Limiting}

To address the role of the enzyme in TCR signaling, the NSM was silenced in primary T cells by siRNA (referred to as NSM KD) or by CRIPSR-Cas9-editing in Jurkat cells (referred to as Jurkat$\Delta \mathrm{NSM})$. NSM silencing in primary $\mathrm{T}$ cells was characterized at the level of RNA by RT-PCR (Figure S1A in Supplementary Material), and enzyme activity was reduced on average by about $50 \%$ in siRNA transfected primary $\mathrm{T}$ cells and by about $70 \%$ in Jurkat- $\Delta$ NSM cells (Figure S1B in Supplementary Material). Ablation of NSM activity in both systems did not affect ASM activity, cell morphology, viability, or sensitivity to induced cell death (Figures S1C-E in Supplementary Material). As described by us earlier (46), ablation of NSM activity rendered T cells highly responsive to $\alpha$-CD3/CD28 co-stimulation using standard conditions ( $\alpha-\mathrm{CD} 3 / \alpha-\mathrm{CD} 28$, each $1 \mu \mathrm{g} / \mathrm{ml})$. This was particularly pronounced $24 \mathrm{~h}$ after activation, however, still visible after $72 \mathrm{~h}$ (Figure 1A). In agreement with enhanced sensitivity to activation, a higher percentage of NSM KD and Jurkat- $\Delta$ NSM cells displayed high membrane order (Figure 1B; Figure S1F in Supplementary Material) supporting the interpretation that NSM is at least dispensable for $\mathrm{T}$ cell activation by co-stimulation.
Ligation of CD3 alone activated, as reported earlier (47), NSM in T cells. This peaked after 2-5 min in Jurkat cells (Figure 1C, left panel) and at 2 and $10 \mathrm{~min}$ in primary CD4+ T cells (Figure 1C, right panel). Pre-exposure to the Src-family kinase inhibitor PP2 prevented $\alpha$-CD3-driven NSM activation thereby placing NSM activation downstream of Lck activity (Figure 1C). Expansion of $\mathrm{T}$ cells after CD3 ligation alone $(1 \mu \mathrm{g} / \mathrm{ml})$ was inefficient, but entirely abolished in NSM KD cells (Figure 1A). Accumulation of tyrosine-phosphorylated protein species was substantially reduced in both NSM KD cells and $\alpha$-CD3-activated Jurkat$\Delta$ NSM cells (Figure 1D and data not shown). These findings confirm that NSM activity supports rather than inhibits TCR signaling in the absence of co-stimulation.

NSM activity is required for TCR signaling, and therefore, hyper-responsiveness of NSM KD cells should result from over-compensation of defective TCR signaling by $\alpha$-CD28 costimulation. This could be directly shown in an experiment in which enhanced sensitivity of proliferative responses of NSM KD cells activated by a constant $\alpha$-CD3 concentration $(100 \mathrm{ng} / \mathrm{ml})$ was only observed at high amounts (at least $10 \mathrm{ng} / \mathrm{ml}$ ) of CD28-specific antibodies (Figure 2A). At lower concentrations of $\alpha$-CD3 antibodies alone (mimicking low antigen dose), proliferative responses were lost in both NSM KD and CTRL cells (Figure 2B, left graph). Using these conditions $(2.5 \mathrm{ng} / \mathrm{ml}$ $\alpha$-CD3), addition of low levels of $\alpha$-CD28 antibodies $(6 \mathrm{ng} / \mathrm{ml})$ still enhanced expansion of CTRL, but less so that of NSM KD cells (Figure 2B, right graph). These findings suggest that the contribution of NSM in TCR signaling could be particularly important in a physiological context where antigen doses are limiting. In support of this hypothesis, NSM KD and CTRL cells were equally efficient in mobilizing $\mathrm{Ca}^{2+}$ at high, but not at low concentrations of stimulatory $\alpha-\mathrm{CD} 3$ antibodies (Figure 2C). Both the kinetics and magnitude of $\mathrm{Ca}^{2+}$ fluxing (reporting signal amplification) were substantially compromised in the absence of NSM. This strongly indicates that NSM activity in TCR signaling is of particular importance in perception and/or amplification of antigenic signals.

\section{NSM Activity Is Required for Sustainment Rather Than Signal Initiation of TCR Signaling}

To identify NSM targets in TCR signaling, we first analyzed very early steps of it. Though NSM activation in response to $\alpha$-CD3 ligation is downstream of the Lck (Figure 1C), ablation of its steady state activity affects overall membrane order and therefore also possibly initiation of TCR signaling (Figure 1B). Because TCR cluster formation and receptor density therein are important in this process by favoring $\mathrm{CD} 3 \zeta$ chain phosphorylation (2), these were analyzed in Jurkat- $\Delta$ NSM cells. To enable comparative monitoring of this and all subsequently described parameters, we used stimulatory $\alpha$-CD3 at saturating concentrations $(1 \mu \mathrm{g} / \mathrm{ml})$. On poly-L-lysine seeded cells were labeled by fluorescent stimulatory $\alpha$-CD3 antibodies and crosslinked by secondary antibodies on ice. To minimize confounding effects by endocytosis (which did not reveal NSM-relating differences) (Figure 3A, IF pictures left; Figure S2B in Supplementary 

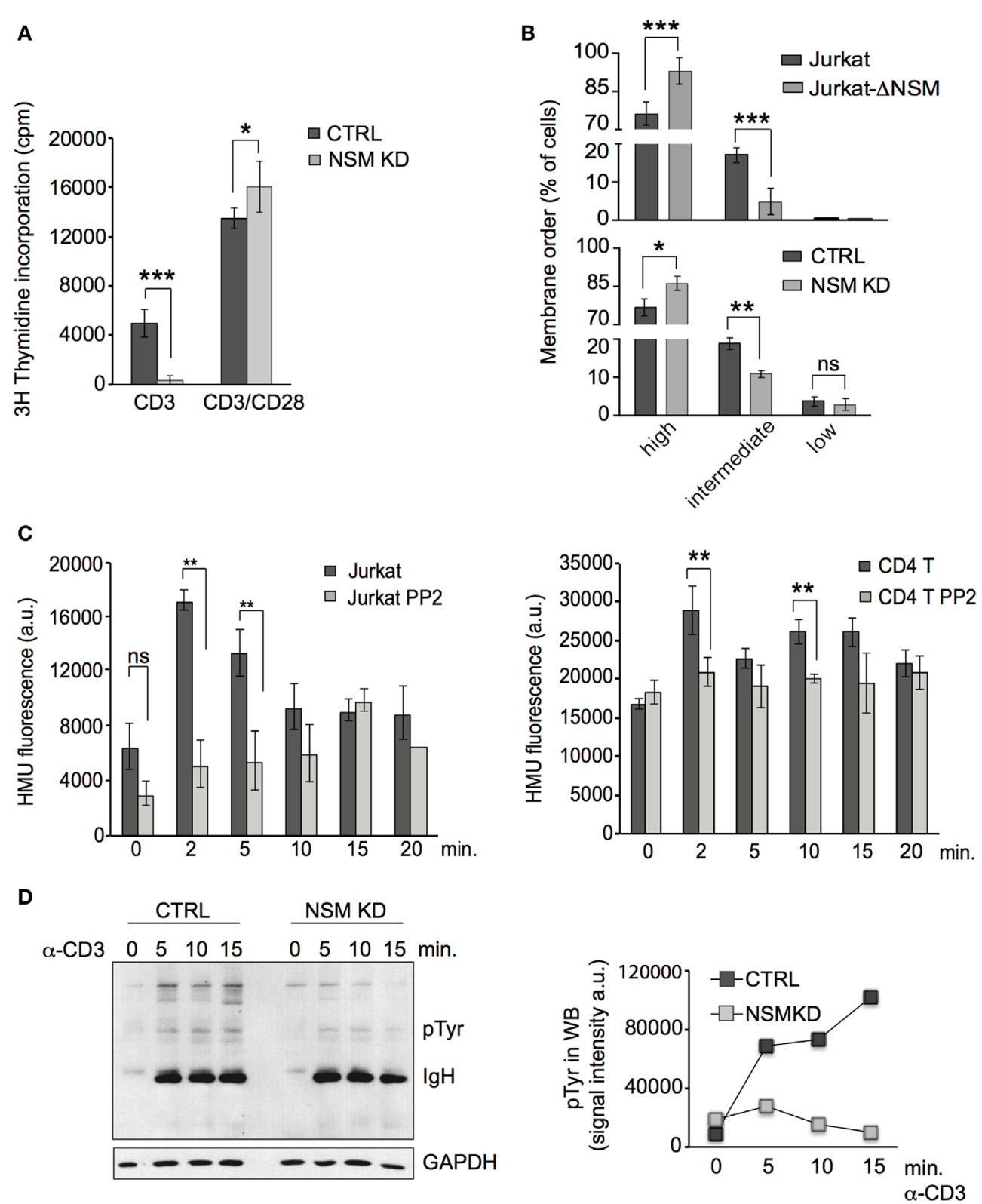

FIGURE 1 | NSM activity is important in T cell receptor signaling. (A) CTRL (black bars) and NSM KD cells (gray bars) were stimulated by ligation of $\alpha$-CD3 alone or in combination with $\alpha$-CD28 $\left(1 \mu \mathrm{g} / \mathrm{ml}\right.$ each) and ${ }^{3} \mathrm{H}$-thymidine incorporation was determined after $72 \mathrm{~h}$. If not stated otherwise, data were obtained and statistically analyzed from at least three independent experiments with SDs indicated. (B) CTRL and NSM KD or parental Jurkat and Jurkat- $\Delta$-NSM cells were stained with ANE and fluorescence emission at 570 and $630 \mathrm{~nm}$ and thereby cell populations revealing high, medium, and low lipid order were distinguished. (C) NSM activity was determined in $\alpha$-CD3-ligated Jurkat (left panel) or primary CD4+ T cells (right panel) pretreated with PP2A (each gray bars) or not (each black bars) over time. (D) Accumulation levels of pTyr protein species were determined in $\alpha$-CD3-activated (1 $\mu \mathrm{g} / \mathrm{ml}$ ) CTRL and NSM KD cells over time (right: densitometry quantification of the lanes shown in the blot, left panel). One out of three independent experiments is shown.

Material) surface clusters were analyzed at the basal outer membrane 5 min after shifting cells to $37^{\circ} \mathrm{C}$ by $d$ STORM. As revealed by quantification, formation of CD3-clusters was not affected in Jurkat- $\Delta$ NSM cells (Figure $\mathbf{3 A}$ ). This also applied to increase in signal density within these clusters following stimulation (Figure S2A in Supplementary Material) indicating that NSM activity is dispensable for TCR signal initiation at that level.
We next addressed whether Lck activity, which is required for $\mathrm{CD} 3 \zeta$ chain phosphorylation, might be affected. Overall levels of phosphorylated Lck had a tendency for slight elevation in NSM KD cells, yet this applied to both the inhibitory (pLck Y505) and the activatory (pLckY394 recognized by pSrcY416 antibody) modification and that was not significant after analysis of independent experiments (Figure 3B; Figure S2C in Supplementary 

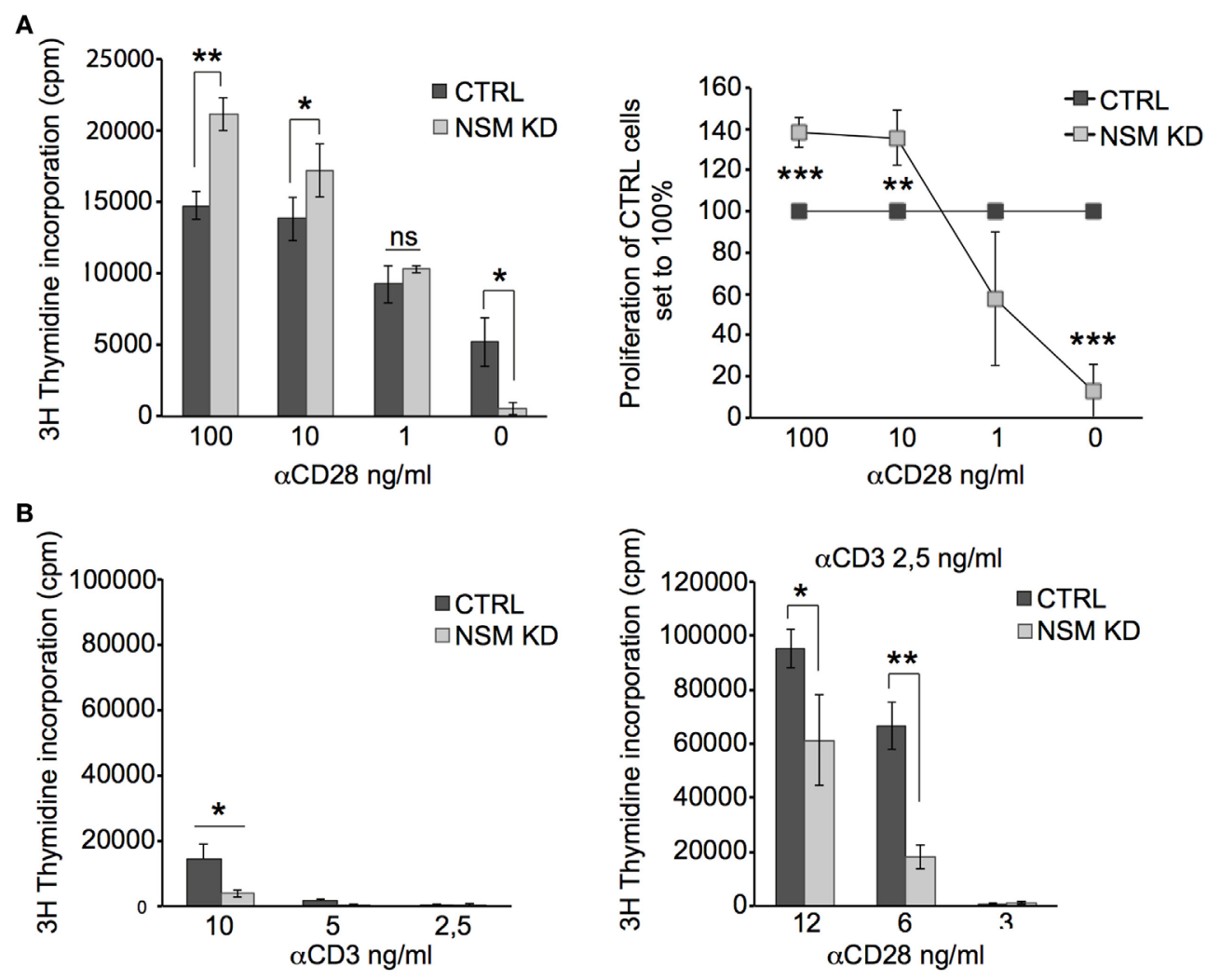

C

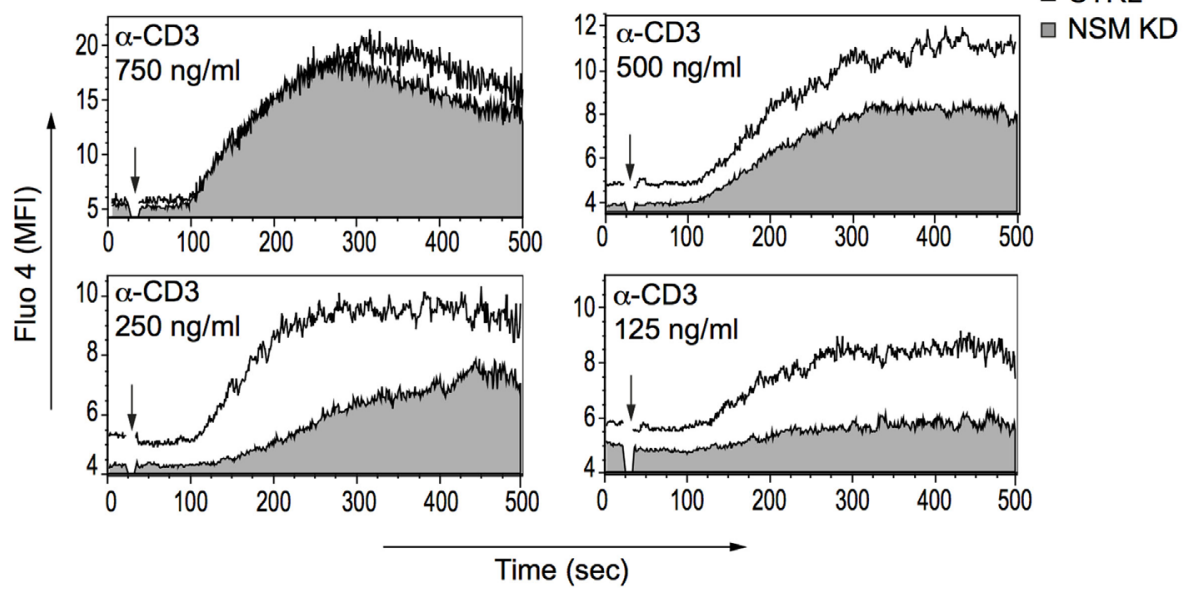

FIGURE 2 | NSM is required for T cell receptor signal amplification at low antigen dose. (A) Proliferation of $\alpha$-CD3-stimulated (0.1 $\mu \mathrm{g} / \mathrm{ml}) \mathrm{CTRL}$ (black bars) and NSM KD cells (gray bars) co-stimulated with decreasing concentrations of $\alpha$-CD28 antibodies was determined after $72 \mathrm{~h}$ (left panel and proliferation of NSM KD cells normalized to that of CTRLs, right panel). (B) Expansion rates were determined in CTRL (black bars) and NSM KD cells (gray bars) stimulated by decreasing concentration of $\alpha$-CD3 antibodies alone (left panel) or by constant $\alpha$-CD3 $(2.5 \mathrm{ng} / \mathrm{ml})$ with decreasing concentrations of $\alpha$-CD28 antibodies after $72 \mathrm{~h}$. (C) Fluo-4 emission signals were recorded in CTRL (white profiles) and NSM KD cells (gray profiles) stimulated by decreasing concentrations of $\alpha$-CD3 antibodies by flow cytometry over time. One representative out of three independent experiments is shown. The time point of $\alpha$-CD3 addition is marked by arrow in each graph.

Material). Moreover, the subcellular distribution of Lck proteins toward pseudo-ISs formed using $\alpha$-CD3-coated beads did not reveal NSM-related differences (data not shown).

Accessibility of the Lck substrate, the $\mathrm{CD} 3 \zeta$ chain, is regulated by a conformational change upon TCR stimulation. Though ini-

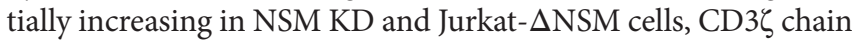

phosphorylation levels were not maintained for longer than $2 \mathrm{~min}$ following stimulation (Figure 3C), which roughly corresponded to the peak of $\alpha$-CD3-driven NSM activation (Figure 1C). $\alpha$-CD3-stimulated phosphorylation of another Lck target, Zap-70, was weakly initiated and returned back to the level of unstimulated cells within $15 \mathrm{~min}$ in the absence of NSM as shown for 
A

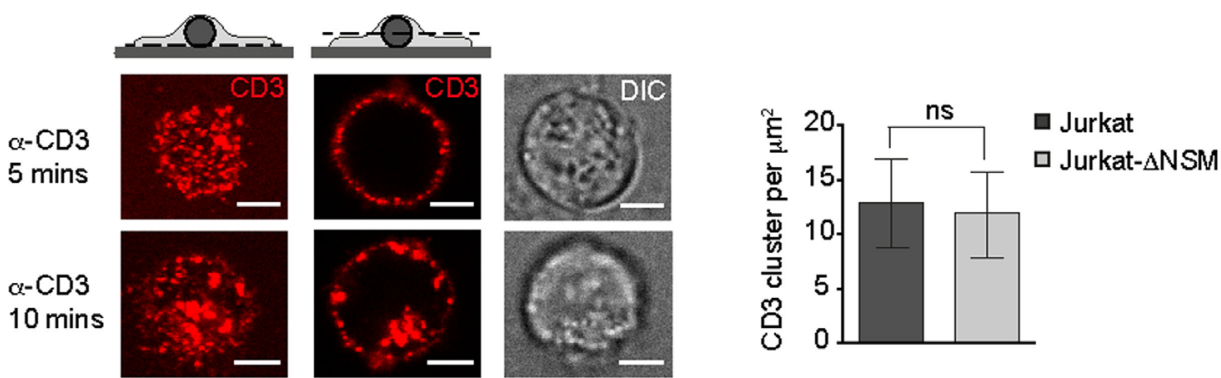

B
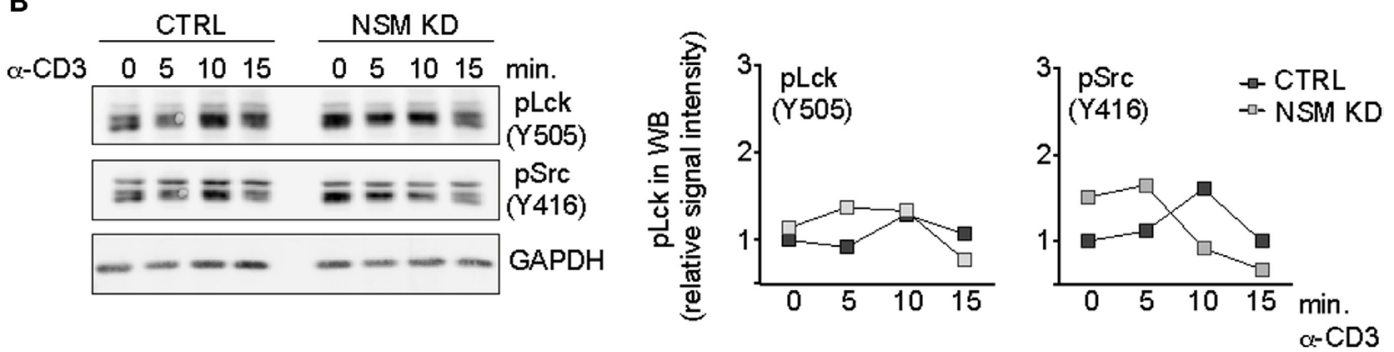

C
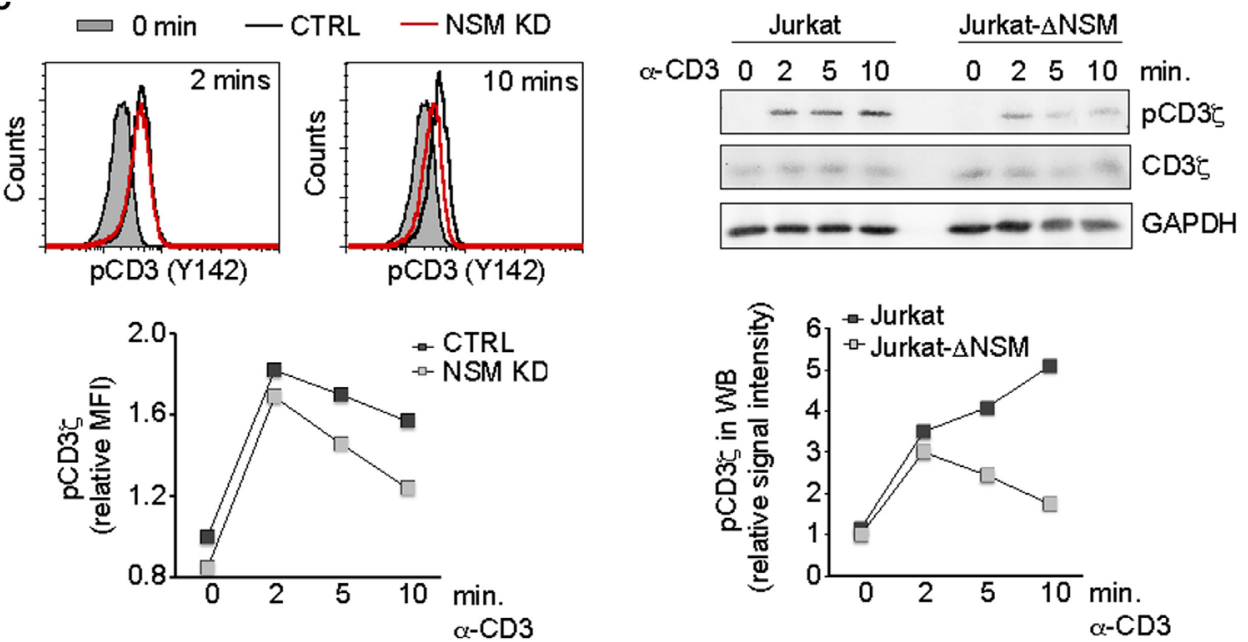

D
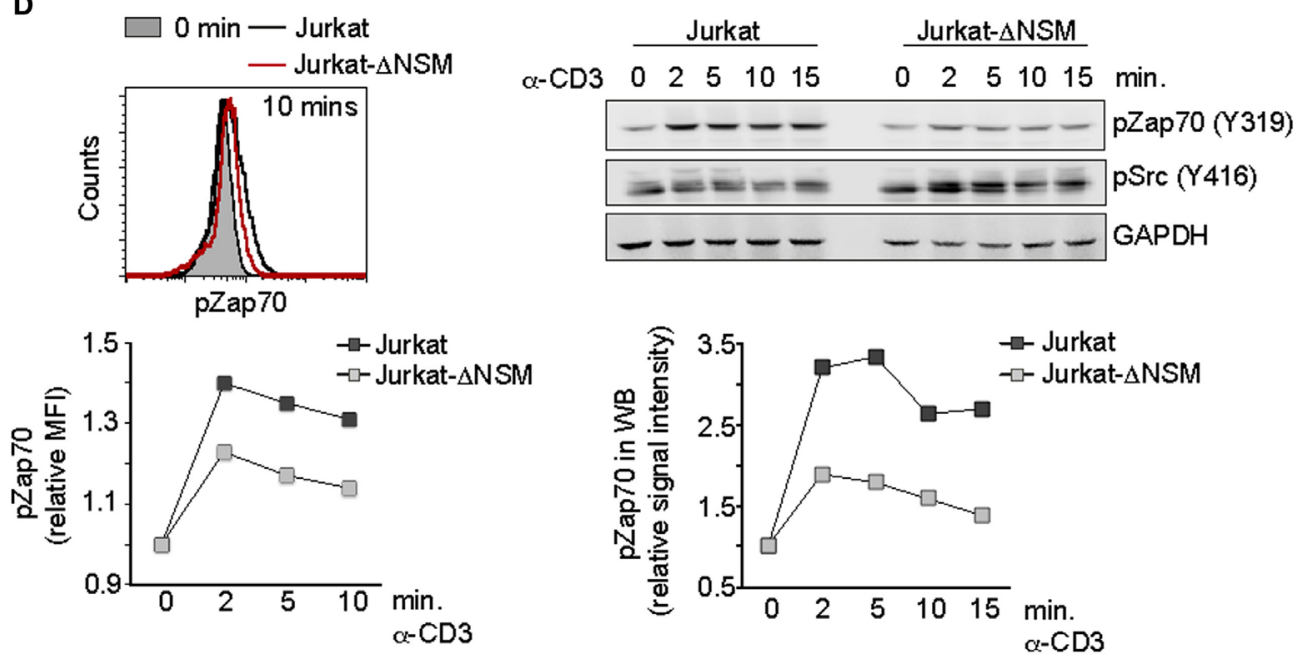

FIGURE 3 | Continued 
FIGURE 3 | NSM activity is dispensable for initiation but not for sustainment of T cell receptor signaling. (A) Parental Jurkat cells were seeded on poly-L-lysin coated slides and stimulated with Alexa647-conjugated $\alpha$-CD3 antibody for 5 and 10 min (IF pictures). CD3 signal localization at the basal plane is shown left (upper left pictogram and left IF pictures). CD3 endocytosis starting after 10 min of stimulation is shown in z-cut through the middle of the cell body (upper right pictogram and IF pictures in the middle). DIC cell morphology pictures are shown right. Scale bars: $5 \mu$ M. Formation of CD3-clusters was analyzed by $d S T O R M$ at 5 min following temperature shift to $37^{\circ} \mathrm{C}$ and fixation. Localization of clusters was identified using DBSCAN algorithm (right graph). (B) Accumulation levels of pLck (Y505) and pSrc(Y416) were determined in $\alpha$-CD3-activated (1 $\mu \mathrm{g} / \mathrm{ml})$ CTRL and NSM KD cells over time. (C) Phosphorylation levels of CD3 $\zeta$ were determined in $\alpha$-CD3-activated [as in (B)] CTRL and NSM KD cells (left panels, by flow cytometry) or in Jurkat and Jurkat-NSM cells (right panels, by Western blot) over time. (D) Phosphorylation of Zap-70 (D) was detected in Jurkat and Jurkat- $\Delta$ NSM by flow cytometry (left panels) and Western blot (right panels). Densitometric quantifications of the signals are shown for each of the Western blots. (B-D) Each one representative out of three independent experiments is shown.

Jurkat- $\Delta$ NSM cells (Figure 3D; Figure S2D in Supplementary Material). This indicates that NSM is not important for the initial membrane proximal wave of TCR signaling within the first 2-5 min, but rather for promoting the second wave of $\mathrm{T}$ cell activation required for signal amplification and sustainment.

\section{Polarization of Signaling Components Is Abrogated in NSM-Deficient T Cells}

$\mathrm{T}$ cell receptor signal propagation and amplification requires cytoskeletal driven polarization of signaling components and subcellular compartments toward the stimulatory interface $(6,7)$. We therefore comparatively analyzed redistribution of TCR $\beta$ in primary NSM KD cells forming pseudo-ISs with $\alpha$-CD3-coated beads (Jurkat cells efficiently internalized stimulatory beads, and therefore, bead assays were generally performed using primary T cells). In contrast to CTRL cells, NSM KD largely failed to accumulate TCR molecules at the pseudo-IS (representatively shown by $3 \mathrm{D}$ reconstruction of the signals, Figure $\mathbf{4 A}$ ). In quantitative terms, this became apparent regardless whether enrichment of the TCR signals were determined in relation to whole cell plasma membrane or cytoplasm (reporting lateral or vertical vesicular trafficking) (Figure 4A). To ensure that decreased TCR fluorescence at the pseudo-IS of NSM KD cells does not result from changes in membrane topology or different membrane folding at the cell-bead interface, CTRL, and NSM KD T cells were loaded with the plasma membrane fluorescent dye octadecyl rhodamine $\mathrm{B}$ chloride R18 and conjugates with beads were analyzed for fluorescence intensity at interaction interface. Broad range of R18 signal intensities was observed in different pseudo-IS, but overall fluorescence intensity distribution was similar in CTRL and NSM KD cells (Figure S3 in Supplementary Material), suggesting that TCR $\beta$ fluorescence enrichment at the interface between T cells and beads does not reflect increased membrane folding. To reveal whether lack of polarization targets also other important TCR signaling components, we analyzed redistribution of Zap-70 toward $\alpha$-CD3-coated beads. As for CD3 $\beta$, Zap-70 pseudo-IS accumulation was substantially impaired in NSM KD cells, with Zap-70 signals found distributed all over the cytoplasm or even at the distal pole of conjugated T cells (Figure 4B). In summary, this attributes a role of NSM in general T cell signaling machinery polarization in response to TCR activation.

\section{PKCs Are NSM Effectors in TCR-Driven T Cell Polarization}

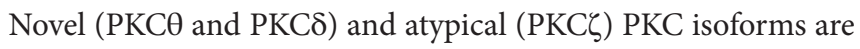

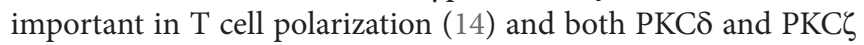

are ceramide effectors (52). To reveal whether they are generally subjected to NSM-dependent regulation (independently of TCR signaling) in T cells, their activation after PMA/ionomycin stimulation was analyzed in parental and Jurkat- $\triangle$ NSM cells. Accumulation of phosphorylated PKC $\delta$ was generally low in Jurkat- $\triangle$ NSM cells and independent of stimulation (Figure 5A; Figure S4A in Supplementary Material, upper graphs). Phosphorylation of $\mathrm{PKC} \theta$ and $\mathrm{PKC} \zeta / \lambda$ was stimulated by PMA/ iono in unmodified Jurkat cells. By contrast, $\mathrm{pPKC} \theta$ and $\mathrm{pPKC} \zeta / \lambda$ phosphorylation levels did not increase in stimulated Jurkat$\Delta$ NSM cells after PMA/ionomycin treatment, even so their phosphorylation was detected in unstimulated Jurkat- $\Delta$ NSM cells in some experiments (Figure 5A; Figure S4A in Supplementary Material). The results indicated that these $\mathrm{PKC}$ isoforms require NSM for stimulation-dependent activity. This was further supported by the almost complete inability of PMA/ionomycin stimulated Jurkat- $\Delta$ NSM cells to produce IL-2, known to rely on activation of PKCs (Figure 5B). Interestingly $\mathrm{PKC} \zeta / \lambda$ phosphorylation was dependent on both TCR stimulation and NSM (Figure 5C; Figure S4B in Supplementary Material), whereas PCK $\theta$ phosphorylation was NSM independent (Figure S5A in Supplementary Material).

Membrane association of PKC is a prerequisite for their activation. We therefore analyzed PKC localization in $\alpha$-CD3activated Jurkat- $\triangle$ NSM cells. Both PKC $\theta$ and PKC $\zeta$ partitioned into DRMs as early as 5 min following activation in control cells. This was not significantly reduced for PKC $\theta$, but almost entirely abrogated for PKC $\zeta$ in Jurkat- $\Delta$ NSM cells (Figure 5D; Figure S4C in Supplementary Material). When these analyses were extended to pseudo-IS polarization of these kinases, NSM-relating differences were not observed for PKCO (Figure S5B in Supplementary Material). By contrast, $\mathrm{PKC} \zeta$ polarization was significantly impaired in NSM KD cells (Figure 5E). This indicated that IS recruitment of PKC $\zeta$, an organizer of cell polarity, requires NSM activity in T cells. In agreement with the $\mathrm{PKC} \zeta$ polarity complex not being adequately recruited to the IS, $\mathrm{Cdc} 42$, a component of this complex required for cytoskeletal reorganization, also failed to accumulate in absence of NSM (Figure S5C in Supplementary Material).

The role of $\mathrm{PKC}$ isoforms in MTOC polarization is established, while that of $\mathrm{PKC}_{\zeta}$ in this process in T cells is not nor its regulation by NSM. Clearly revealing the importance of this enzyme in MTOC polarization, MTOC pseudo-IS translocation was inefficient in NSM KD cells as measured by the distance between the center of the bead and the MTOC signal (Figure 6A). Similarly, in a planar system, control, but not Jurkat- $\Delta$ NSM cells efficiently polarized the MTOC, and this was abrogated in control cells upon inhibition of PKC $\zeta$ by PZI (Figures 6B,C). 


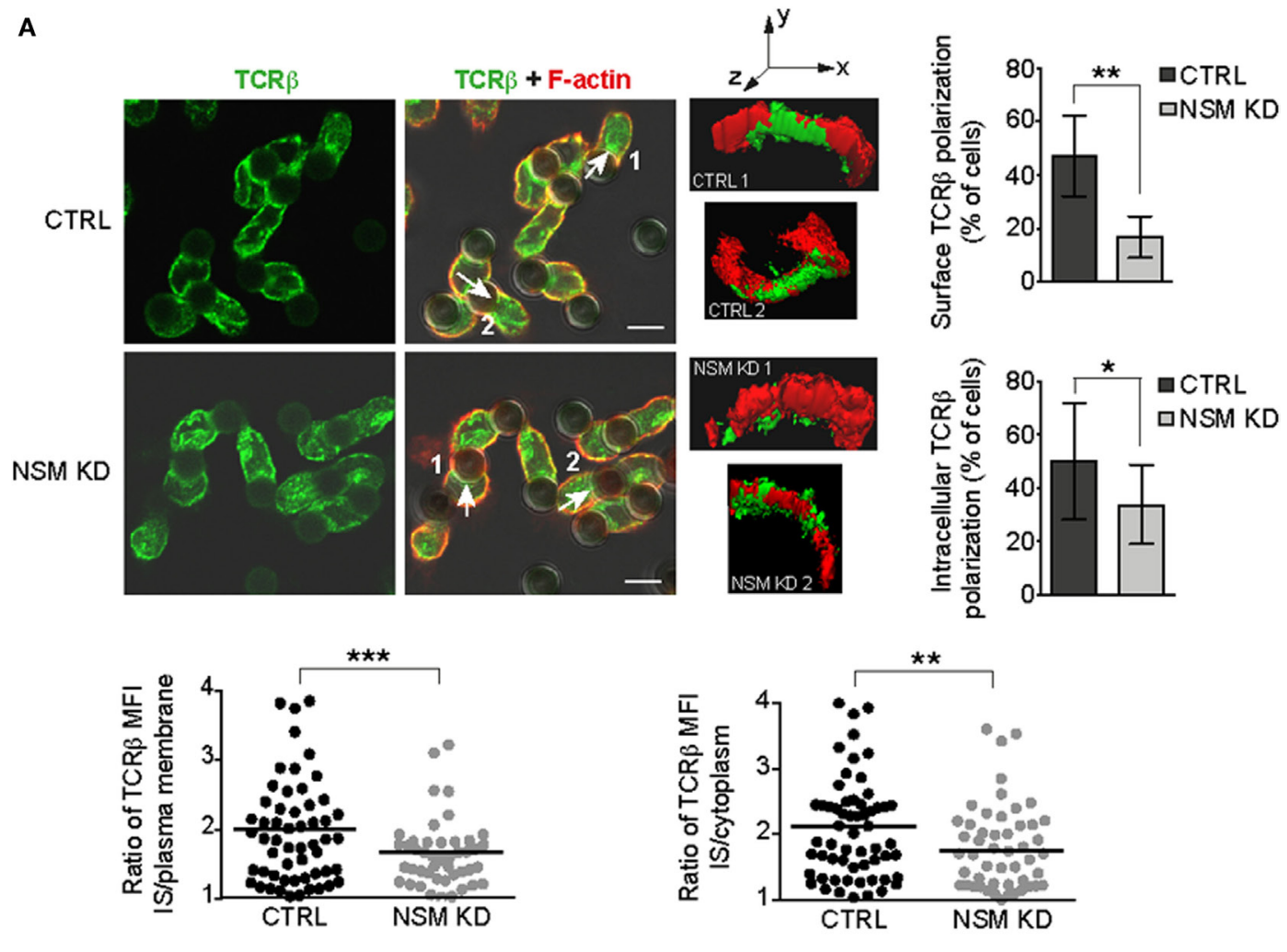

B
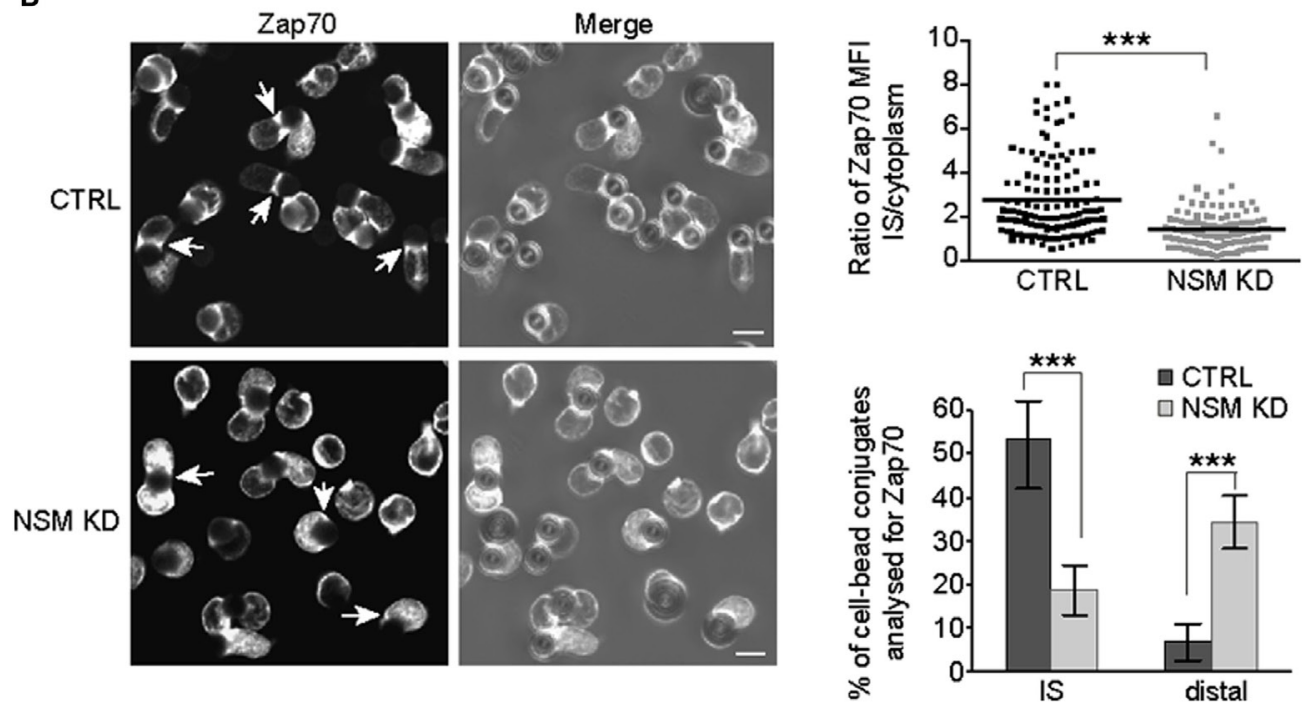

FIGURE 4 | NSM activity is required for immune synapse (IS) polarization of T cell receptor (TCR) signaling components. CTRL and NSM KD cells were stimulated by $\alpha$-CD3-coated beads and redistribution of TCR $\beta$ (A) and Zap70 (B) was determined after 15 min. (A) TCR $\beta$ was co-detected with F-actin (IF shown in left panels, right panels showing 3D reconstruction of the cell-bead IS areas indicated in the IF merge pictures by numbers and arrows). IS interface accumulation was counted as positive if relative fluorescence increase at IS of each individual cell (depicted in scatter plots) was more than 1.5 in relation to surface fluorescence intensity or intracellular accumulation. The results are shown as \% of cells with positive interface accumulation of TCR $\beta$ (column bar graphs). (B) Zap-70 redistribution was analyzed as in (A) with regard to relative IS recruitment of the intracellular pool. In addition, Zap-70 re-positioning to the distal pole was observed in NSM KD cells where fluorescence intensity was more than two times higher in cell region most distal to the cell-bead interface (right bottom graph). (A,B) Size bars represent $5 \mu \mathrm{m}$.

Microtubule-organizing center translocation to the IS is of particular importance in sustained TCR signaling, and its relocalization relies on both PKC activation and dynamic reorganization of the microtubular network $(7,14)$. As established for non-T cells,
NSM can regulate microtubular stability during cilia formation $(53,54)$. Therefore, abrogation of PKC $\zeta$ IS recruitment might be accompanied by de-regulation of microtubular dynamics in NSM-depleted cells, thereby affecting both MTOC anchoring 
A

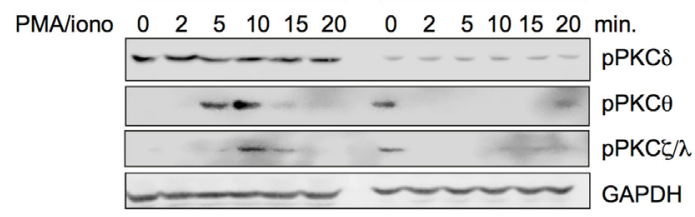

C

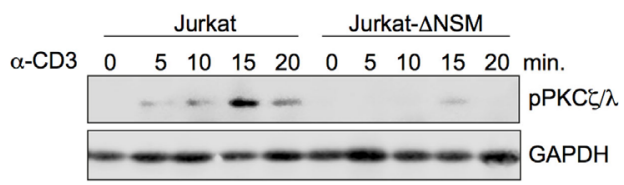

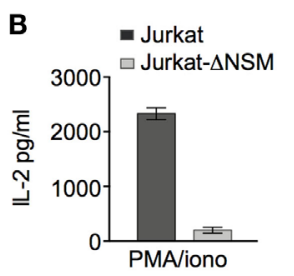

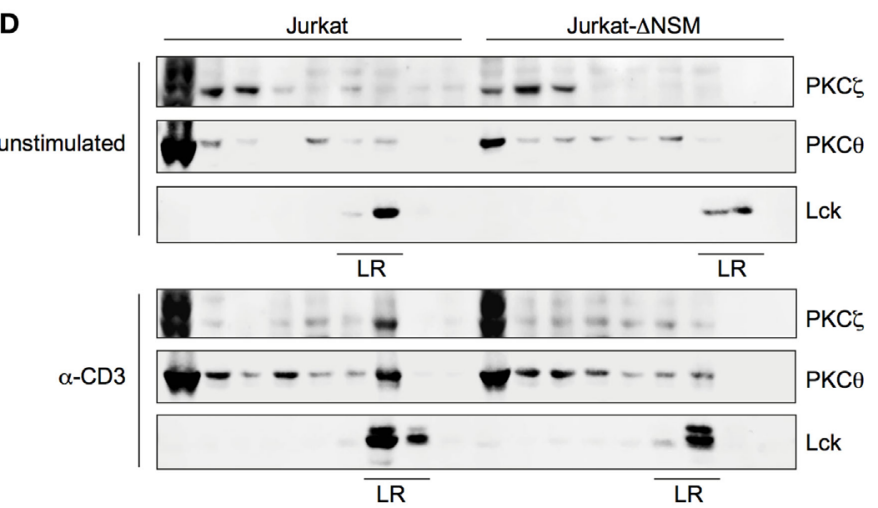

E
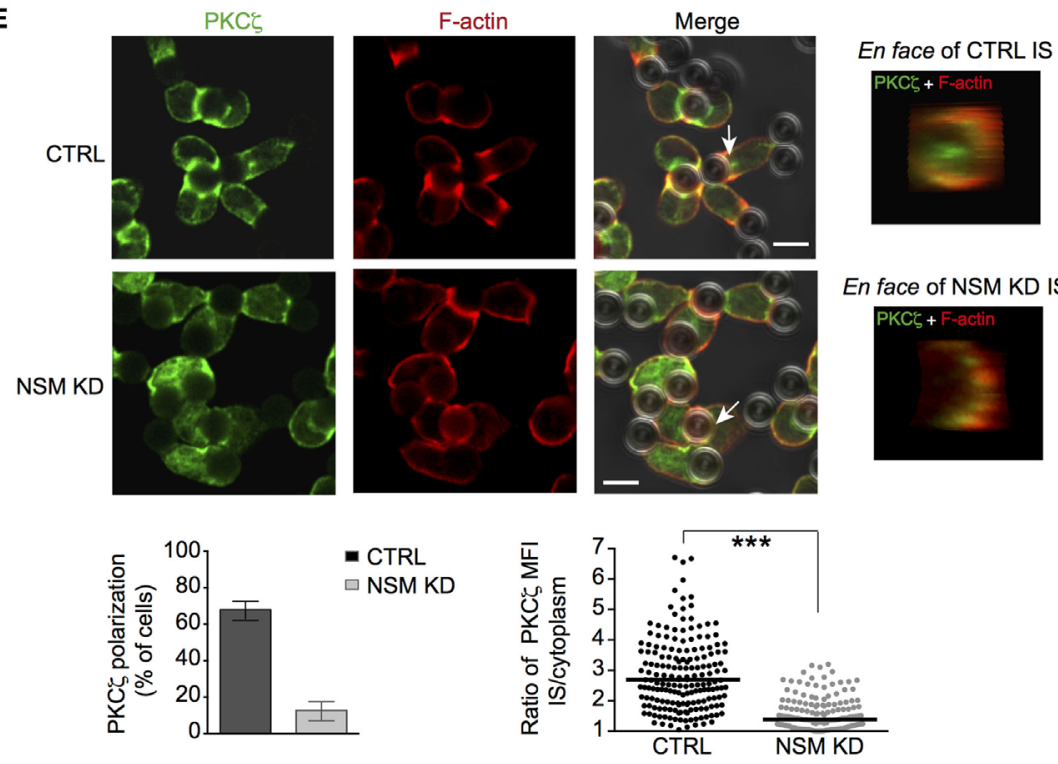

FIGURE $5 \mid$ PKC is an NSM downstream effector. (A,B) Jurkat- $\triangle$ NSM and control cells were stimulated with PMAiionomycin. Accumulation of pPKC 8, pPKC $\theta$, and $\mathrm{pPKC} / \lambda$ was determined over time (A) and IL-2-release after $48 \mathrm{~h}$ (B). (C) Accumulation of pPKC $\zeta / \lambda$ was determined in Jurkat- $\Delta$ NSM and control cells stimulated with $\alpha$-CD3 over time. (D) Detergent resistant membrane (DRM) domain association of PKC $\zeta$ and PKC $\theta$ was determined in unstimulated (upper panels) and in 5 min $\alpha$-CD3-stimulated (bottom panels) parental and Jurkat- $\triangle$ NSM cells (detection of Lck was used to identify DRM fractions). (E) PKC $\zeta$ and F-actin were co-detected in CTRL (IF panels, upper row) or NSM KD cells (IF panels, bottom row) 15 min after stimulation with $\alpha$-CD3-coated beads. The percentage of cells

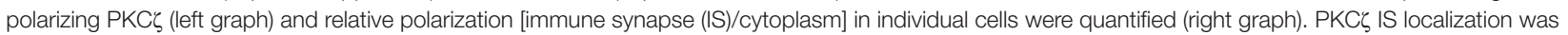
visualized by en face view (representative examples are shown in IF pictures on the right side). Size bars: $5 \mu \mathrm{M}$.

and vesicular transport. Indeed, TCR stimulation-dependent accumulation of tubulin stabilized by acetylation was strongly compromised in NSM KD and Jurkat- $\triangle$ NSM cells (Figure 6D;
Figure S5D in Supplementary Material). Detyrosinated tubulin located at the MTOC initiates microtubule growth and provides mechanical forces pushing MTOC toward IS. Strikingly, almost 
A

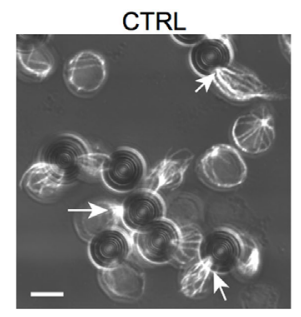

B

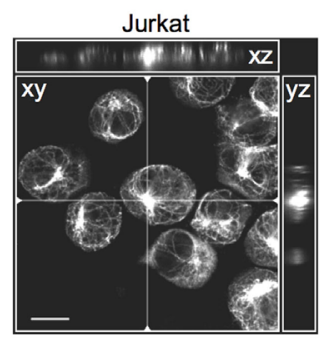

C

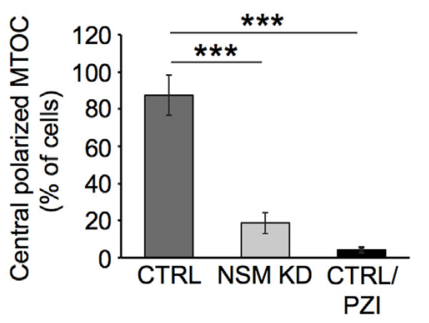

NSM KD
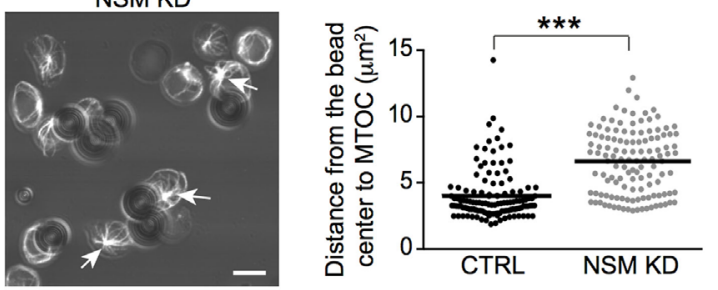

E
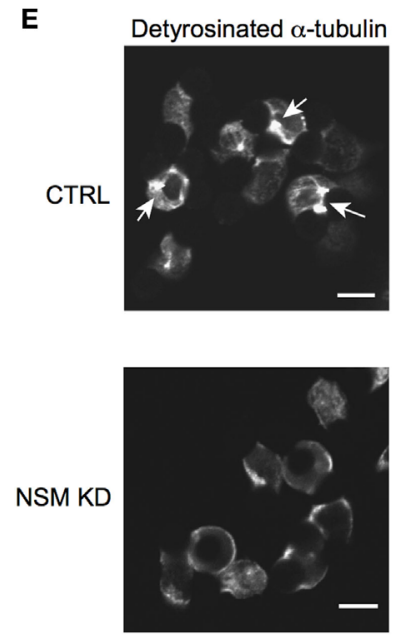

Jurkat- $\triangle N S M$

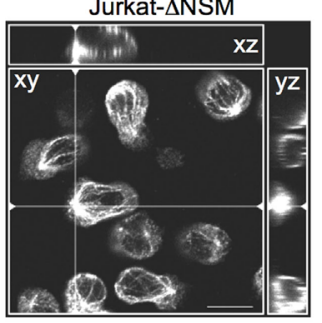

D

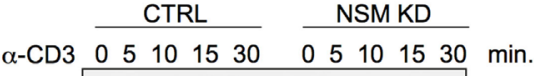
\begin{tabular}{|ll}
\hline$-\cdots-\cdots$ & acetyl- $\alpha$-tubulin \\
\hline$-\cdots-\cdots-$ tubulin
\end{tabular} Jurkat Jurkat- $\triangle$ NSM $\alpha-C D 3 \quad 0 \quad 510 \quad 15 \quad 30 \quad 0 \quad 5101530$ min.

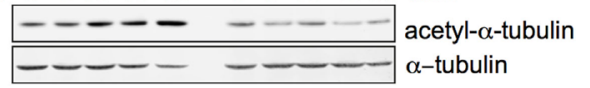
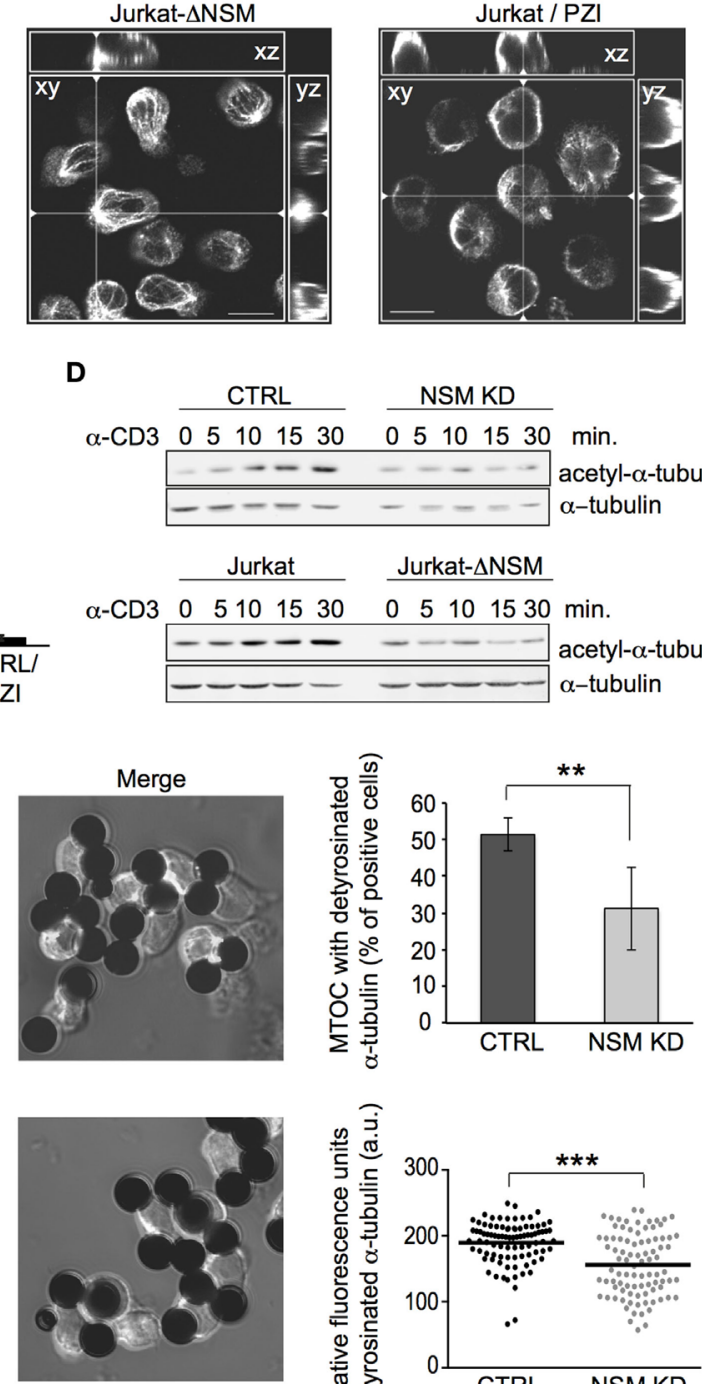

\section{.}


$50 \%$ of MTOCs recorded in bead-conjugated NSM KD cells did not stain for detyrosinated tubulin (Figure 6E, upper right panel). NSM KD cells retaining detyrosinated MTOC tubulin revealed markedly reduced fluorescence signal intensities for that tubulin modification (Figure 6E, lower right panel). Altogether, these data reveal that TCR-driven IS recruitment of essential polarity complex components (PKC $\zeta, \mathrm{Cdc} 42$ ), its downstream effector (MTOC) and microtubular dynamics are substantially impaired in the absence of NSM.

\section{PKC $\zeta$ Recruitment to DRM Domains and MTOC Polarization Are Rescued by Ceramide Supplementation}

Because NSM causes ceramide release and PKC $\zeta$ is a ceramide effector, NSM-related defects in TCR signaling might be rescued by ceramide supplementation. To reveal whether it would redistribute to lipid rafts in parental or Jurkat- $\Delta$ NSM cells, we fed the azido-functionalized $\mathrm{C}_{16}$-ceramide $\left(\omega\right.$ - $\mathrm{C}_{16}$-cer) to both cultures. Cells were DIBO-Alexa-488 clicked, $\alpha$-CD3-stimulated for $5 \mathrm{~min}$ and imaged or used for floatation analysis. Under the conditions used, $\omega$ - $\mathrm{C}_{16}$-cer was efficiently incorporated and not toxic for parental and Jurkat- $\Delta$ NSM cells (as revealed by viability dye staining, data not shown). As its $\omega-\mathrm{C}_{6}$-ceramide counterpart, $\omega$ - $\mathrm{C}_{16}$-cer accumulated both in the plasma membrane and an intracellular (most likely, the Golgi) compartment (51) (Figure 7A, IF insets). Upon fluorescence analysis of gradient fractions, the clicked $\omega-\mathrm{C}_{16}$-cer also accumulated in fractions in which bona fide DRM resident proteins, such as Lck, LAT, $\mathrm{CD} 3 \zeta$, and $\mathrm{CD} 3 \varepsilon$ were detectable (Figure 7A) indicating that exogenous $\mathrm{C}_{16}$ indeed incorporated into TCR containing DRMs after $\alpha$-CD3 stimulation. Of note, incorporation of $\omega$ - $\mathrm{C}_{16}$-cer into CD3, Lck, and LAT enriched fractions upon stimulation was more efficient in NSM-sufficient cells (Figure 7A, bottom graphs).

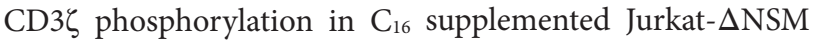
cells 5 minafter stimulation was similar to that in wild type Jurkat cells, while overall phosphorylation levels were reduced (Figure S6A in Supplementary Material). The reduced phosphorylation possibly resulted from the lack of tight regulation of local ceramide generation in time, normally occurring during TCR engagement. Importantly, supplementation of $\mathrm{C}_{16}$-ceramide rescued partitioning of $\mathrm{PKC} \zeta$ into DRM fractions in $\alpha$-CD3stimulated Jurkat- $\triangle$ NSM cells (Figures $5 \mathrm{D}$ and 7B; Figure S6B in Supplementary Material) and MTOC polarization toward the stimulatory surface (Figure 7C). Active GSK-3 destabilizes microtubules in immature thymocytes and its inactivation is dependent on atypical PKCs in the primary cilium $(55,56)$. Pretreatment with the GSK-3 inhibitor IMO rescued the ability of Jurkat- $\triangle$ NSM cells to translocate the MTOC, thereby lending further support to the importance of $\mathrm{PKC} \zeta$ as NSM and ceramide effector in stabilization of microtubuli (Figure 7C). This shows that TCR-dependent NSM activation promotes spatiotemporal formation of ceramide-enriched domains essential for $\mathrm{T}$ cell polarization, signal sustainment and amplification, and this is especially important when antigen dose or co-stimulation efficiencies are limiting.

\section{DISCUSSION}

With its potential to modify primarily the cytosolic leaflet of the plasma membrane, the NSM bears the potential to organize microdomains and thereby, formation of receptor-proximal signaling clusters (57). Pointing to its importance in T cells activation, its enzymatic activity is transiently induced by TCR ligation in the presence and absence of co-stimulation $(46,47)$. We now established that the NSM functions to organize sustained T cell activation which is driven by cytoskeletal-dependent polarization of signaling components toward the nascent IS, and thereby allows for signal stabilization, amplification, and sustainment. We further show that recruitment and activation of atypical PKC $\zeta$ is crucial in this process.

NSM-depleted T cells were found hyper-responsive to costimulation, which suggested a role of the enzyme in regulating threshold activities (46). Our refined study confirmed NSM as essential in TCR signaling, and that hyper-responsiveness of NSM KD cells reflected the response to optimal stimulation where neither antigen nor levels of co-stimulatory ligand were limiting. Inside-out signaling of TCR can enhance the avidity of CD28 ligand binding and license CD28 to access TCR downstream effector pathways and thereby driving and amplifying $\mathrm{T}$ cell activation $(58,59)$. Therefore, $\mathrm{T}$ cells lacking signaling components especially required for cytoskeletal re-arrangements in sustaining of signal (such as NSM) can be efficiently activated only when co-stimulatory signals are particularly strong. This scenario is perfectly reflected by our findings that $T$ cells need NSM for signal amplification at low antigen doses and unsaturated CD28-support (Figure 2B). Stimulation in the absence of NSM is dependent on highly efficient CD28 ligation (Figure 2A). To avoid co-stimulation dependent hyper-responses of NSMdepleted cells and to analyze NSM-dependent TCR signaling without co-engagement of $\mathrm{CD} 28$, we used antibody-based stimulation approaches lacking antigen-presenting cells.

T cell receptor-mediated NSM activation was PP2A sensitive and therefore expected to occur downstream of Lck activation (Figure 1C). Because overall lipid order is increased in NSMdepleted $\mathrm{T}$ cells, the enzyme also contributes to the steady state lipid composition (and loss of its activity is not compensated by ASM activity) (Figure 1B; Figures S1B,C,F in Supplementary Material). The ANEP dye reports accumulation of lipid ordered domains rather than specific contributing lipids, not allowing to draw conclusions on involved sphingolipid species. NSMdependent membrane steady state lipid modulations could well affect initiation of TCR signaling because sphingomyelin and ceramides can regulate lateral mobility and clustering of proteins as well as lipid composition in membrane domains $(60,61)$. Therefore, TCR $\beta$ chain cholesterol interaction, TCR nanocluster formation, or TCR proximal nanodomain net charge essentially regulating conformational changes and accessibility of $\mathrm{CD} 3 \varepsilon$ and $\mathrm{CD} 3 \zeta$ chains could have been potentially subject to regulation by basal NSM activity $(2,17$, 20, 21, 62). Extensive dSTROM based analyses did, however, not substantiate a role of NSM in TCR nanocluster formation. Because we focused on TCR signal initiation and labeled CD3 antibodies were internalized at later time points (at equal 

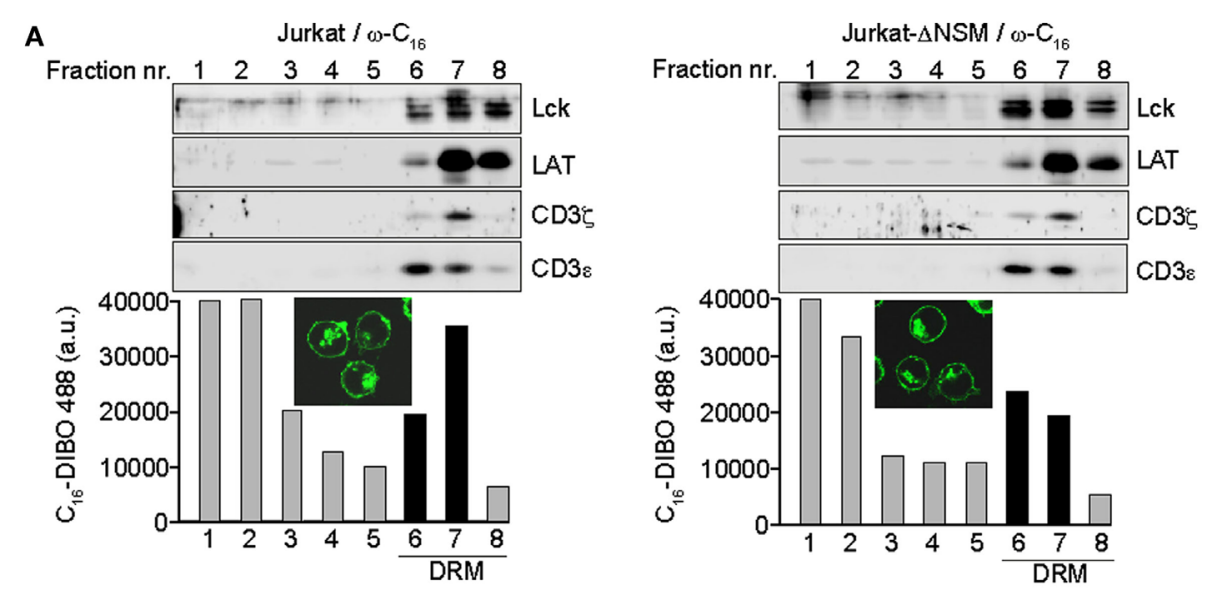

B

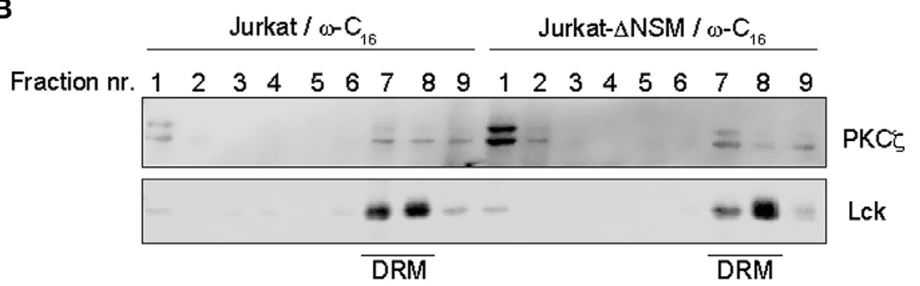

C
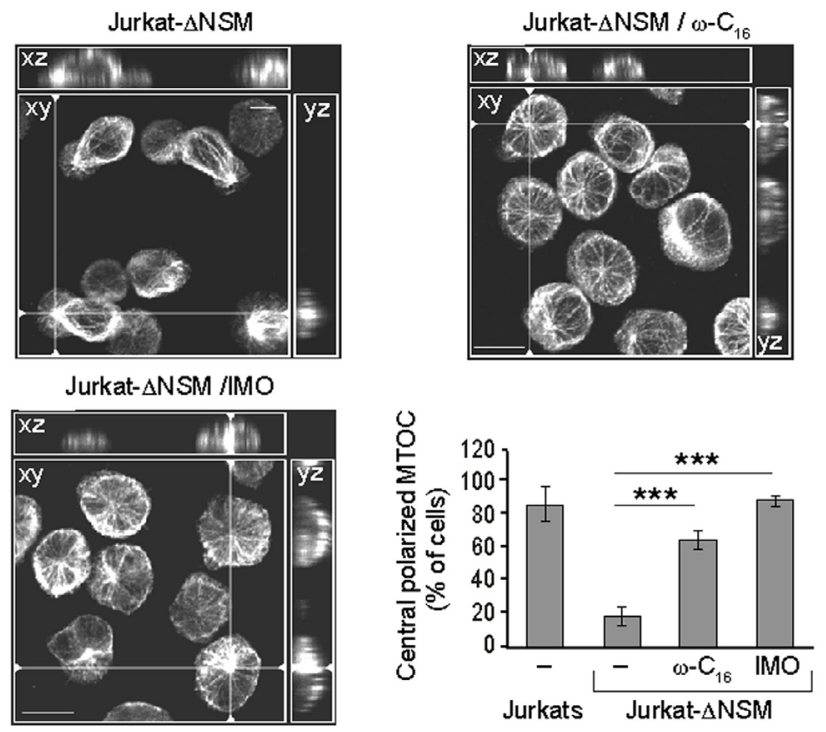

FIGURE 7 | Ceramide supplementation rescues PKC detergent resistant membrane (DRM) association and microtubule-organizing center (MTOC) polarization in $\alpha$-CD3-stimulated NSM-depleted T cells. (A) Parental and Jurkat- $\triangle$ NSM cells were loaded with functionalized $\omega$-C16-ceramide, DIBO488-clicked and analyzed by

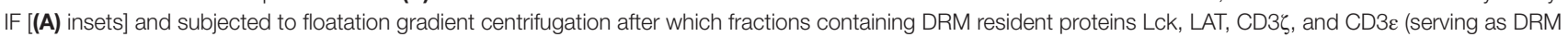
markers) were identified by Western blot (upper panels) and accumulation of DIBO488 was measured in all fractions by fluorescence reader (bottom panels). (B) DRM domain association of PKC $\zeta$ was determined after 5 min of $\alpha$-CD3-stimulation of parental and Jurkat- $\Delta$ NSM cells pre-loaded with $\omega$ - $C_{16}$-Ceramide (detection of Lck was used to identify DRM fractions). (C) Jurkat- $\triangle$ NSM loaded with $\omega$ - $\mathrm{C}_{16}$-cermide or pretreated with the GSK3-inhibitor indirubin-3'-monoxime were $\alpha$-CD3 stimulated. Graph shows the percentage of MTOC polarizing cells quantified after 15 min of stimulation as described in Figures $6 \mathbf{B}, \mathbf{C}$. Representative IF pictures for each condition are shown. Size bar: $10 \mu \mathrm{M}$. (A-C) One representative experiment out of three is shown.

efficiencies in NSM-sufficient and -deficient cells, Figure S2B in Supplementary Material), our analyses were restricted to the first $5 \mathrm{~min}$ after stimulation. NSM-related differences in formation of TCR microclusters with regard to number, CD3 densities, and size were not observed (Figure 3A; Figure S2A in Supplementary Material and data not shown). Surprisingly, cluster densities in all cultures did not substantially increase upon stimulation, which was reported to enhance the likelihood of $\mathrm{CD} 3 \zeta$ chain phosphorylation (2). Because $\mathrm{CD} 3 \zeta$ chain phosphorylation levels were initially also not affected by the absence of NSM, we considered the mechanistic insight into discrepancies on the increase in cluster density between our 
and the published work (2) not within the focus of this manuscript and did not follow this aspect further.

As it is PP2 sensitive, NSM activity is not required for signaling initiation. The enzyme activity detectably increased within $2 \mathrm{~min}$ and declined thereafter in Jurkat and was biphasic in primary T cells (Figure 1C), while the earlier study reported peak NSM activities after 15 or 30 min in Jurkat, T cell hybridoma, and murine spleen cells (47). This different kinetic may represent differential assay sensitivities or stimulation protocols. In common to both studies, $\mathrm{pCD} 3 \zeta$ was unaffected within the first 2 min of $\mathrm{T}$ cell stimulation. While this was not further followed in the Tonnetti study (47), we found that amplification-dependent sustainment of $\mathrm{CD} 3 \zeta$ and Zap-70 phosphorylation could only be fulfilled in the presence of NSM, which was instrumental in supporting organization of a polarized vesicular sorting complex.

Extracellular vesicles of endosomal origin: exosomes are important mediators of $\mathrm{T}$ cell responses. They can transfer biologically active miRNA from $\mathrm{T}$ cells to antigen-presenting cells through immunological synapse (63) and their biogenesis in the lumen of endosomes is dependent on ceramide generated by NSM2 (64). T cells increase exosome secretion upon activation. They contain Lck, c-Cbl, and activated TCR/CD3 complexes, suggesting their role as vehicles specifically delivering signaling molecules to the site of immunological synapse in polarized fashion (65). Deficient exosome production in $\mathrm{T}$ cells lacking NSM could be another reason for poor TCR $\beta$, Zap70, and PKC $\zeta$ polarization toward $\mathrm{T}$ cell and stimulatory bead synapse.

T cell receptor effectors activating NSM remain to be identified. A fraction of NSM associates with the plasma membrane also in T cells (46), and anionic lipids, particularly phosphatidylserine (PS), are known activators (66). The latter also promotes TCR signal initiation $(17,20)$ suggesting that co-sorting and/or close proximity with TCR microclusters may promote NSM activation. Low abundancy of ceramides within the CD3 lipidome seems to suggest that NSM does not act in close proximity to TCR microclusters (32). Potential co-segregation of NSM with the TCR within membrane microdomains would be highly interesting to look at, was, however, beyond the scope of the present study, which focused on NSM downstream effectors in TCR signaling rather than mechanism upstream NSM activation.

Our study identified the polarity complex protein $\mathrm{PKC \zeta}$ as a major effector in NSM-dependent TCR signaling. Although nearly all protein components of polarity complex of other cell types are found in T cells, its regulation and functions upon TCR engagement at the IS is poorly understood (67). A central role of PKC $\zeta$ in formation of the polarity complex in epithelial cells is well documented $(68,69)$. This atypical PKC also regulates chemokine-induced integrin activation and polarization in effector T cells (70), and we have recently shown that SDF- $1 \alpha$ driven physical $\mathrm{T}$ cell polarization on fibronectin and inflamed endothelial cells is also NSM dependent (71). The ability of PKC $\zeta$ to bind ceramide and its role in cilia formation in stem cells and neural progenitors and in polarization of primitive ectodermal cells has been previously established $(54,56,72,73)$. Prevention of ceramide accumulation by pharmacologic inhibition of ceramide synthase or NSM enabled HDAC6-dependent destabilization of primary cilia indicating that NSM participates in this process via activation of atypical PKCs (54). In agreement with these findings, genetic ablation of NSM prevented PKCS membrane recruitment (Figures 5D,E), thereby showing a link between TCR-dependent NSM activation and IS recruitment of central polarity complex protein $\mathrm{PKC}$. As highly relevant for sustainment of T cell responses, depletion of NSM substantially compromised recruitment of TCR downstream effector Zap-70 toward the IS (Figure 4B). The unique role of NSM as upstream regulator in this scenario is supported by data showing that exogenous ceramides efficiently rescue $\mathrm{PKC} \zeta$ membrane recruitment and MTOC relocalization (Figures $\mathbf{7 B}, \mathbf{C}$ ). The ability of exogenous ceramides, which primarily insert into the outer membrane leaflet $(51,74-76)$ to substitute for activation of proteins and pathways relying on NSM activity has been revealed earlier $(47,54)$. Whether this involves ceramide flipping or accumulation of ceramides at inner leaflet due to transbilayer communication has so far not been experimentally amenable.

PKC $\zeta$ is not only a ceramide but also a PS and phosphatic acid (PA)-binding and -activated protein, and these lipid species are also enriched in IS microdomains (20, 77-79). Though not formally proven in our study, NSM activity may not affect compartmentalized PS or PA accumulation there, because it does not target TCR conformational changes (relying on PS) and Lck activity (required for DGKa activation, translocation to the IS periphery and subsequent PA generation by DAG phosphorylation). Intriguingly, both PA and ceramide accumulate in the IS periphery where centripetal actin and microtubular dependent transport of microclusters is initiated and MTOC anchoring via microtubuli takes place $(46,77,80)$. It is therefore quite possible that TCR activated NSM and subsequent ceramide release is crucial for organizing microdomains and patterning other lipids such as $\mathrm{PA}$ that recruit $\mathrm{PKC} \zeta$ to promote polarization and stabilization of $\mathrm{T}$ cell activation.

\section{ETHICS STATEMENT}

This study (use of primary human T cells) was carried out in accordance with the recommendations of "name of guidelines, name of committee"; with written informed consent from all subjects. All subjects gave written informed consent in accordance with the Declaration of Helsinki. The protocol was approved by the "Ethical Committee Medical Faculty University of Wuerzburg."

\section{AUTHOR CONTRIBUTIONS}

Conceptualization: AD, MS, SS-S, and EA; Methodology: RS, $\mathrm{CB}, \mathrm{AK}$, and EA; Formal analysis: $\mathrm{CB}, \mathrm{AK}$ and EA; Experimental investigation: $\mathrm{CB}, \mathrm{RS}, \mathrm{AK}$, and EA; Writing: EA and SS-S; Funding acquisition: $\mathrm{MS}, \mathrm{AD}$, and SS-S; Resources: AD, RS, and AK; Supervision: MS, EA, and SS-S.

\section{ACKNOWLEDGMENTS}

We thank Erich Gulbins, Lars Dölken, Niklas Beyersdorf, and Jürgen Schneider-Schaulies for critically reading the manuscript; Jürgen Seibel and Tim Walter (Department for Organic Chemistry, 
University of Wuerzburg) for providing azido-functionalized ceramide; and Philipp Kible for excellent technical assistance. The work was funded through the Deutsche Forschungsgemeinschaft within the RU 2123 (DFG SCHN 405/10) and the University of Wuerzburg within the funding program 'Open Access Publishing'.

\section{REFERENCES}

1. Ngoenkam J, Schamel WW, Pongcharoen S. Selected signalling proteins recruited to the T-cell receptor-CD3 complex. Immunology (2017) 153(1): 42-50. doi:10.1111/imm.12809

2. Pageon SV, Tabarin T, Yamamoto Y, Ma Y, Bridgeman JS, Cohnen A, et al. Functional role of T-cell receptor nanoclusters in signal initiation and antigen discrimination. Proc Natl Acad Sci U S A (2016) 113(37):E5454-63. doi:10.1073/pnas.1607436113

3. Rossy J, Owen DM, Williamson DJ, Yang Z, Gaus K. Conformational states of the kinase Lck regulate clustering in early T cell signaling. Nat Immunol (2013) 14:82-9. doi:10.1038/ni.2488

4. Rossy J, Williamson DJ, Benzing C, Gaus K. The integration of signaling and the spatial organization of the T cell synapse. Front Immunol (2012) 3: 352. doi:10.3389/fimmu.2012.00352

5. Williamson DJ, Owen DM, Rossy J, Magenau A, Wehrmann M, Gooding JJ, et al. Pre-existing clusters of the adaptor Lat do not participate in early T cell signaling events. Nat Immunol (2011) 12:655-62. doi:10.1038/ni.2049

6. Martin-Cofreces NB, Baixauli F, Sanchez-Madrid F. Immune synapse: conductor of orchestrated organelle movement. Trends Cell Biol (2014) 24:61-72. doi:10.1016/j.tcb.2013.09.005

7. Martin-Cofreces NB, Robles-Valero J, Cabrero JR, Mittelbrunn M, GordonAlonso M, Sung $\mathrm{CH}$, et al. MTOC translocation modulates IS formation and controls sustained T cell signaling. J Cell Biol (2008) 182:951-62. doi:10.1083/ jcb. 200801014

8. Blas-Rus N, Bustos-Moran E, Perez de Castro I, de Carcer G, Borroto A, Camafeita E, et al. Aurora A drives early signalling and vesicle dynamics during T-cell activation. Nat Commun (2016) 7:11389. doi:10.1038/ncomms11389

9. Hashimoto-Tane A, Yokosuka T, Sakata-Sogawa K, Sakuma M, Ishihara C, Tokunaga $\mathrm{M}$, et al. Dynein-driven transport of $\mathrm{T}$ cell receptor microclusters regulates immune synapse formation and $\mathrm{T}$ cell activation. Immunity (2011) 34:919-31. doi:10.1016/j.immuni.2011.05.012

10. Lasserre R, Alcover A. Cytoskeletal cross-talk in the control of $\mathrm{T}$ cell antigen receptor signaling. FEBS Lett (2010) 584:4845-50. doi:10.1016/j.febslet. 2010.09.001

11. Neve-Oz Y, Razvag Y, Sajman J, Sherman E. Mechanisms of localized activation of the $\mathrm{T}$ cell antigen receptor inside clusters. Biochim Biophys Acta (2015) 1853:810-21. doi:10.1016/j.bbamcr.2014.09.025

12. Yi J, Wu XS, Crites T, Hammer JA III. Actin retrograde flow and actomyosin II arc contraction drive receptor cluster dynamics at the immunological synapse in Jurkat T cells. Mol Biol Cell (2012) 23:834-52. doi:10.1091/mbc. E11-08-0731

13. Martin-Cofreces NB, Baixauli F, Lopez MJ, Gil D, Monjas A, Alarcon B, et al. End-binding protein 1 controls signal propagation from the $\mathrm{T}$ cell receptor. EMBO J (2012) 31:4140-52. doi:10.1038/emboj.2012.242

14. Quann EJ, Liu X, Altan-Bonnet G, Huse M. A cascade of protein kinase C isozymes promotes cytoskeletal polarization in T cells. Nat Immunol (2011) 12:647-54. doi:10.1038/ni.2033

15. Bustos-Moran E, Blas-Rus N, Martin-Cofreces NB, Sanchez-Madrid F. Microtubule-associated protein- 4 controls nanovesicle dynamics and T cell activation. J Cell Sci (2017) 130:1217-23. doi:10.1242/jcs.199042

16. Wu W, Shi X, Xu C. Regulation of T cell signalling by membrane lipids. Nat Rev Immunol (2016) 16:690-701. doi:10.1038/nri.2016.103

17. Lopez CA, Sethi A, Goldstein B, Wilson BS, Gnanakaran S. Membranemediated regulation of the intrinsically disordered $\mathrm{CD} 3$ cytoplasmic tail of the TCR. Biophys J (2015) 108:2481-91. doi:10.1016/j.bpj.2015.03.059

18. Schamel WW, Alarcon B, Hofer T, Minguet S. The allostery model of TCR regulation. J Immunol (2017) 198:47-52. doi:10.4049/jimmunol.1601661

19. Sheng R, Jung DJ, Silkov A, Kim H, Singaram I, Wang ZG, et al. Lipids regulate Lck activity through their interactions with the Lck SH2 domain. J Biol Chem (2016) 291(34):17639-50. doi:10.1074/jbc.M116.720284

\section{SUPPLEMENTARY MATERIAL}

The Supplementary Material for this article can be found online at https://www.frontiersin.org/articles/10.3389/fimmu.2018.00815/ full\#supplementary-material.

20. Shi X, Bi Y, Yang W, Guo X, Jiang Y, Wan C, et al. $\mathrm{Ca}^{2+}$ regulates T-cell receptor activation by modulating the charge property of lipids. Nature (2013) 493:111-5. doi:10.1038/nature11699

21. Swamy M, Beck-Garcia K, Beck-Garcia E, Hartl FA, Morath A, Yousefi OS, et al. A cholesterol-based allostery model of $\mathrm{T}$ cell receptor phosphorylation. Immunity (2016) 44:1091-101. doi:10.1016/j.immuni.2016.04.011

22. Wang F, Beck-Garcia K, Zorzin C, Schamel WW, Davis MM. Inhibition of $\mathrm{T}$ cell receptor signaling by cholesterol sulfate, a naturally occurring derivative of membrane cholesterol. Nat Immunol (2016) 17:844-50. doi:10.1038/ ni. 3462

23. Kapoor-Kaushik N, Hinde E, Compeer EB, Yamamoto Y, Kraus F, Yang Z, et al. Distinct mechanisms regulate Lck spatial organization in activated T cells. Front Immunol (2016) 7:83. doi:10.3389/fimmu.2016.00083

24. Park MJ, Sheng R, Silkov A, Jung DJ, Wang ZG, Xin Y, et al. SH2 Domains serve as lipid-binding modules for pTyr-signaling proteins. Mol Cell (2016) 62:7-20. doi:10.1016/j.molcel.2016.01.027

25. Rossy J, Williamson DJ, Gaus K. How does the kinase Lck phosphorylate the $\mathrm{T}$ cell receptor? Spatial organization as a regulatory mechanism. Front Immunol (2012) 3:167. doi:10.3389/fimmu.2012.00167

26. Lasserre R, Guo XJ, Conchonaud F, Hamon Y, Hawchar O, Bernard AM, et al. Raft nanodomains contribute to Akt/PKB plasma membrane recruitment and activation. Nat Chem Biol (2008) 4:538-47. doi:10.1038/nchembio.103

27. Parry RV, Riley JL, Ward SG. Signalling to suit function: tailoring phosphoinositide 3-kinase during T-cell activation. Trends Immunol (2007) 28:161-8. doi:10.1016/j.it.2007.02.004

28. Lasserre R, Charrin S, Cuche C, Danckaert A, Thoulouze MI, de Chaumont F, et al. Ezrin tunes T-cell activation by controlling Dlg1 and microtubule positioning at the immunological synapse. EMBO J (2010) 29:2301-14. doi:10.1038/ emboj.2010.127

29. Gaus K, Chklovskaia E, Fazekas de St Groth B, Jessup W, Harder T. Condensation of the plasma membrane at the site of T lymphocyte activation. J Cell Biol (2005) 171:121-31. doi:10.1083/jcb.200505047

30. Miguel L, Owen DM, Lim C, Liebig C, Evans J, Magee AI, et al. Primary human $\mathrm{CD} 4+\mathrm{T}$ cells have diverse levels of membrane lipid order that correlate with their function. JImmunol (2011) 186:3505-16. doi:10.4049/ jimmunol.1002980

31. Rentero C, Zech T, Quinn CM, Engelhardt K, Williamson D, Grewal T, et al. Functional implications of plasma membrane condensation for $\mathrm{T}$ cell activation. PLoS One (2008) 3:e2262. doi:10.1371/journal.pone. 0002262

32. Zech T, Ejsing CS, Gaus K, de Wet B, Shevchenko A, Simons K, et al. Accumulation of raft lipids in T-cell plasma membrane domains engaged in TCR signalling. EMBO J (2009) 28:466-76. doi:10.1038/emboj.2009.6

33. Sonnino S, Prinetti A. Membrane domains and the "lipid raft" concept. Curr Med Chem (2013) 20:4-21. doi:10.2174/09298673130103

34. Adam D, Heinrich M, Kabelitz D, Schutze S. Ceramide: does it matter for T cells? Trends Immunol (2002) 23:1-4. doi:10.1016/S1471-4906(01)02091-9

35. Bollinger CR, Teichgraber V, Gulbins E. Ceramide-enriched membrane domains. Biochim Biophys Acta (2005) 1746:284-94. doi:10.1016/j.bbamcr. 2005.09.001

36. Grassme H, Riethmuller J, Gulbins E. Biological aspects of ceramideenriched membrane domains. Prog Lipid Res (2007) 46:161-70. doi:10.1016/ j.plipres.2007.03.002

37. Gulbins E, Dreschers S, Wilker B, Grassme H. Ceramide, membrane rafts and infections. J Mol Med (2004) 82:357-63. doi:10.1007/s00109-004-0539-y

38. Hannun YA, Obeid LM. Principles of bioactive lipid signalling: lessons from sphingolipids. Nat Rev Mol Cell Biol (2008) 9:139-50. doi:10.1038/ nrm2329

39. Kolesnick RN, Goni FM, Alonso A. Compartmentalization of ceramide signaling: physical foundations and biological effects. J Cell Physiol (2000) 184 285-300. doi:10.1002/1097-4652(200009)184:3<285::AID-JCP2>3.0.CO;2-3 
40. Becker KA, Gellhaus A, Winterhager E, Gulbins E. Ceramide-enriched membrane domains in infectious biology and development. Subcell Biochem (2008) 49:523-38. doi:10.1007/978-1-4020-8831-5_20

41. Ruvolo PP. Intracellular signal transduction pathways activated by ceramide and its metabolites. Pharmacol Res (2003) 47:383-92. doi:10.1016/S10436618(03)00050-1

42. Schneider-Schaulies J, Schneider-Schaulies S. Sphingolipids in viral infection. Biol Chem (2015) 396:585-95. doi:10.1515/hsz-2014-0273

43. Bai A, Kokkotou E, Zheng Y, Robson SC. Role of acid sphingomyelinase bioactivity in human CD4+ T-cell activation and immune responses. Cell Death Dis (2015) 6:e1828. doi:10.1038/cddis.2015.178

44. Church LD, Hessler G, Goodall JE, Rider DA, Workman CJ, Vignali DA, et al. TNFR1-induced sphingomyelinase activation modulates TCR signaling by impairing store-operated Ca2+ influx. J Leukoc Biol (2005) 78:266-78. doi:10.1189/jlb.1003456

45. Lepple-Wienhues A, Belka C, Laun T, Jekle A, Walter B, Wieland U, et al. Stimulation of CD95 (Fas) blocks T lymphocyte calcium channels through sphingomyelinase and sphingolipids. Proc Natl Acad Sci U S A (1999) 96:13795-800. doi:10.1073/pnas.96.24.13795

46. Mueller N, Avota E, Collenburg L, Grassme H, Schneider-Schaulies S. Neutral sphingomyelinase in physiological and measles virus induced T cell suppression. PLoS Pathog (2014) 10:e1004574. doi:10.1371/journal.ppat. 1004574

47. Tonnetti L, Veri MC, Bonvini E, D’Adamio L. A role for neutral sphingomyelinase-mediated ceramide production in $\mathrm{T}$ cell receptor-induced apoptosis and mitogen-activated protein kinase-mediated signal transduction. J Exp Med (1999) 189:1581-9. doi:10.1084/jem.189.10.1581

48. Tellier E, Negre-Salvayre A, Bocquet B, Itohara S, Hannun YA, Salvayre R, et al. Role for furin in tumor necrosis factor alpha-induced activation of the matrix metalloproteinase/sphingolipid mitogenic pathway. Mol Cell Biol (2007) 27:2997-3007. doi:10.1128/MCB.01485-06

49. Crotzer VL, Mabardy AS, Weiss A, Brodsky FM. T cell receptor engagement leads to phosphorylation of clathrin heavy chain during receptor internalization. J Exp Med (2004) 199:981-91. doi:10.1084/jem.20031105

50. Schindelin J, Arganda-Carreras I, Frise E, Kaynig V, Longair M, Pietzsch T, et al. Fiji: an open-source platform for biological-image analysis. Nat Methods (2012) 9:676-82. doi:10.1038/nmeth.2019

51. Collenburg L, Walter T, Burgert A, Muller N, Seibel J, Japtok L, et al. A functionalized sphingolipid analogue for studying redistribution during activation in living T cells. J Immunol (2016) 196:3951-62. doi:10.4049/ jimmunol.1502447

52. Parent N, Scherer M, Liebisch G, Schmitz G, Bertrand R. Protein kinase C-delta isoform mediates lysosome labilization in DNA damage-induced apoptosis. Int J Oncol (2011) 38:313-24. doi:10.3892/ijo.2010.881

53. He Q, Wang G, Dasgupta S, Dinkins M, Zhu G, Bieberich E. Characterization of an apical ceramide-enriched compartment regulating ciliogenesis. Mol Biol Cell (2012) 23:3156-66. doi:10.1091/mbc.E12-02-0079

54. He Q, Wang G, Wakade S, Dasgupta S, Dinkins M, Kong JN, et al. Primary cilia in stem cells and neural progenitors are regulated by neutral sphingomyelinase 2 and ceramide. Mol Biol Cell (2014) 25:1715-29. doi:10.1091/ mbc.E13-12-0730

55. Cunningham NR, Hinchcliff EM, Kutyavin VI, Beck T, Reid WA, Punt JA. GSK3-mediated instability of tubulin polymers is responsible for the failure of immature CD4+CD8+ thymocytes to polarize their MTOC in response to TCR stimulation. Int Immunol (2011) 23:693-700. doi:10.1093/intimm/ dxr076

56. Wang G, Krishnamurthy K, Bieberich E. Regulation of primary cilia formation by ceramide. JLipid Res (2009) 50:2103-10. doi:10.1194/jlr.M900097JLR200

57. Wu BX, Clarke CJ, Hannun YA. Mammalian neutral sphingomyelinases: regulation and roles in cell signaling responses. Neuromolecular Med (2010) 12(4):320-30. doi:10.1007/s12017-010-8120-z

58. Sanchez-Lockhart M, Kim M, Miller J. Cutting edge: a role for inside-out signaling in TCR regulation of CD28 ligand binding. J Immunol (2011) 187:5515-9. doi:10.4049/jimmunol.1102497

59. Sanchez-Lockhart M, Rojas AV, Fettis MM, Bauserman R, Higa TR, Miao $\mathrm{H}$, et al. $\mathrm{T}$ cell receptor signaling can directly enhance the avidity of
CD28 ligand binding. PLoS One (2014) 9:e89263. doi:10.1371/journal.pone. 0089263

60. Eich C, Manzo C, Keijzer S, Bakker GJ, Reinieren-Beeren I, Garcia-Parajo MF, et al. Changes in membrane sphingolipid composition modulate dynamics and adhesion of integrin nanoclusters. Sci Rep (2016) 6:20693. doi:10.1038/ srep20693

61. Zhang Y, Li X, Becker KA, Gulbins E. Ceramide-enriched membrane domains - structure and function. Biochim Biophys Acta (2009) 1788:178-83. doi:10.1016/j.bbamem.2008.07.030

62. Gagnon E, Schubert DA, Gordo S, Chu HH, Wucherpfennig KW. Local changes in lipid environment of TCR microclusters regulate membrane binding by the CD3epsilon cytoplasmic domain. J Exp Med (2012) 209:2423-39. doi: $10.1084 /$ jem. 20120790

63. Mittelbrunn M, Gutierrez-Vazquez C, Villarroya-Beltri C, Gonzalez S, Sanchez-Cabo F, Gonzalez MA, et al. Unidirectional transfer of microRNA-loaded exosomes from T cells to antigen-presenting cells. Nat Commun (2011) 2:282. doi:10.1038/ncomms1285

64. Trajkovic K, Hsu C, Chiantia S, Rajendran L, Wenzel D, Wieland F, et al. Ceramide triggers budding of exosome vesicles into multivesicular endosomes. Science (2008) 319:1244-7. doi:10.1126/science.1153124

65. Blanchard N, Lankar D, Faure F, Regnault A, Dumont C, Raposo G, et al. TCR activation of human $T$ cells induces the production of exosomes bearing the TCR/CD3/zeta complex. JImmunol (2002) 168:3235-41. doi:10.4049/ jimmunol.168.7.3235

66. Airola MV, Shanbhogue P, Shamseddine AA, Guja KE, Senkal CE, Maini R, et al. Structure of human nSMase2 reveals an interdomain allosteric activation mechanism for ceramide generation. Proc Natl Acad Sci U S A (2017) 114:E5549-58. doi:10.1073/pnas.1705134114

67. Russell S, Oliaro J. Compartmentalization in T-cell signalling: membrane microdomains and polarity orchestrate signalling and morphology. Immunol Cell Biol (2006) 84:107-13. doi:10.1111/j.1440-1711.2005.01415.x

68. Kim SK. Cell polarity: new PARtners for Cdc42 and Rac. Nat Cell Biol (2000) 2:E143-5. doi:10.1038/35019620

69. Liu XF, Ishida H, Raziuddin R, Miki T. Nucleotide exchange factor ECT2 interacts with the polarity protein complex Par6/Par3/protein kinase Czeta (PKCzeta) and regulates PKCzeta activity. Mol Cell Biol (2004) 24:6665-75. doi:10.1128/MCB.24.15.6665-6675.2004

70. Gerard A, Mertens AE, van der Kammen RA, Collard JG. The Par polarity complex regulates Rap1- and chemokine-induced T cell polarization. J Cell Biol (2007) 176:863-75. doi:10.1083/jcb.200608161

71. Collenburg L, Beyersdorf N, Wiese T, Arenz C, Saied EM, Becker-Flegler KA, et al. The activity of the neutral sphingomyelinase is important in $\mathrm{T}$ cell recruitment and directional migration. Front Immunol (2017) 8:1007. doi:10.3389/fimmu.2017.01007

72. Krishnamurthy K, Wang G, Silva J, Condie BG, Bieberich E. Ceramide regulates atypical PKCzeta/lambda-mediated cell polarity in primitive ectoderm cells. A novel function of sphingolipids in morphogenesis. J Biol Chem (2007) 282:3379-90. doi:10.1074/jbc.M607779200

73. Wang G, Silva J, Krishnamurthy K, Tran E, Condie BG, Bieberich E. Direct binding to ceramide activates protein kinase Czeta before the formation of a pro-apoptotic complex with PAR-4 in differentiating stem cells. J Biol Chem (2005) 280:26415-24. doi:10.1074/jbc.M501492200

74. Burgert A, Schlegel J, Becam J, Doose S, Bieberich E, Schubert-Unkmeir A, et al. Characterization of plasma membrane ceramides by super-resolution microscopy. Angew Chem Int Ed Engl (2017) 56:6131-5. doi:10.1002/anie. 201700570

75. Walter T, Collenburg L, Japtok L, Kleuser B, Schneider-Schaulies S, Muller N, et al. Incorporation and visualization of azido-functionalized N-oleoyl serinol in Jurkat cells, mouse brain astrocytes, 3T3 fibroblasts and human brain microvascular endothelial cells. Chem Commun (Camb) (2016) 52: 8612-4. doi:10.1039/c6cc02879a

76. Walter T, Schlegel J, Burgert A, Kurz A, Seibel J, Sauer M. Incorporation studies of clickable ceramides in Jurkat cell plasma membranes. Chem Commun (2017) 53:6836-9. doi:10.1039/c7cc01220a

77. Baldanzi G, Bettio V, Malacarne V, Graziani A. Diacylglycerol kinases: shaping diacylglycerol and phosphatidic acid gradients to control cell polarity. Front cell Dev Biol (2016) 4:140. doi:10.3389/fcell.2016.00140 
78. Baldanzi G, Cutrupi S, Chianale F, Gnocchi V, Rainero E, Porporato P, et al. Diacylglycerol kinase-alpha phosphorylation by Src on Y335 is required for activation, membrane recruitment and Hgf-induced cell motility. Oncogene (2008) 27:942-56. doi:10.1038/sj.onc.1210717

79. Tobias IS, Kaulich M, Kim PK, Simon N, Jacinto E, Dowdy SF, et al. Protein kinase Czeta exhibits constitutive phosphorylation and phosphatidylinositol-3, 4,5-triphosphate-independent regulation. Biochem J (2016) 473:509-23. doi:10.1042/BJ20151013

80. Burkhardt JK, Carrizosa E, Shaffer MH. The actin cytoskeleton in T cell activation. Annu Rev Immunol (2008) 26:233-59. doi:10.1146/annurev.immunol. 26.021607.090347
Conflict of Interest Statement: The authors declare that the research was conducted in the absence of any commercial or financial relationships that could be construed as a potential conflict of interest.

Copyright (c) 2018 Börtlein, Draeger, Schoenauer, Kuhlemann, Sauer, SchneiderSchaulies and Avota. This is an open-access article distributed under the terms of the Creative Commons Attribution License (CC BY). The use, distribution or reproduction in other forums is permitted, provided the original author(s) and the copyright owner are credited and that the original publication in this journal is cited, in accordance with accepted academic practice. No use, distribution or reproduction is permitted which does not comply with these terms. 